\title{
Climate modification by future ice sheet changes and consequences for ice sheet mass balance
}

\author{
M. Vizcaíno · U. Mikolajewicz · J. Jungclaus · \\ G. Schurgers
}

Received: 28 July 2008/Accepted: 29 April 2009/Published online: 27 June 2009

(C) Springer-Verlag 2009

\begin{abstract}
The future evolution of global ice sheets under anthropogenic greenhouse forcing and its impact on the climate system, including the regional climate of the ice sheets, are investigated with a comprehensive earth system model consisting of a coupled Atmosphere-Ocean General Circulation Model, a dynamic vegetation model and an ice sheet model. The simulated control climate is realistic enough to permit a direct coupling of the atmosphere and ice sheet components, avoiding the use of anomaly coupling, which represents a strong improvement with respect to previous modelling studies. Glacier ablation is calculated with an energy-balance scheme, a more physical approach than the commonly used degree-day method. Modifications of glacier mask, topographic height and freshwater fluxes by the ice sheets influence the atmosphere and ocean via dynamical and thermodynamical processes. Several simulations under idealized scenarios of greenhouse forcing have been performed, where the atmospheric carbon dioxide stabilizes at two and four times pre-industrial levels. The evolution of the climate system and the ice sheets in the simulations with interactive ice sheets is compared with the simulations with passively coupled ice sheets. For a four-times $\mathrm{CO}_{2}$ scenario forcing,
\end{abstract}

M. Vizcaíno (凹) · U. Mikolajewicz · J. Jungclaus ·

G. Schurgers

Max-Planck-Institut für Meteorologie, Bundestrasse 53,

20146 Hamburg, Germany

e-mail: mirenvt@atmos.berkeley.edu

M. Vizcaíno

Department of Geography, University of California,

Berkeley, CA, USA

G. Schurgers

Department of Physical Geography and Ecosystems Analysis,

Lund University, Lund, Sweden a faster decay rate of the Greenland ice sheet is found in the non-interactive case, where melting rates are higher. This is caused by overestimation of the increase in near-surface temperature that follows the reduction in topographic height. In areas close to retreating margins, melting rates are stronger in the interactive case, due to changes in local albedo. Our results call for careful consideration of the feedbacks operating between ice sheets and climate after substantial decay of the ice sheets.

Keywords Ice sheets - Anthropogenic climate change Feedbacks in the climate system - Meridional overturning circulation · Earth system modelling

\section{Introduction}

Global warming caused by anthropogenic greenhouse gas emissions has the potential to cause important changes in the current mass balance of global ice sheets. The continental-sized glaciers on Earth, the ice sheets of Greenland (GrIS) and Antarctica (AIS), store an amount of freshwater that, in case of being released to the world oceans, would raise sea-level by 7.2 and $61.1 \mathrm{~m}$, respectively (Church et al. 2001). Besides the impact of changing ice sheets on sea level, other potential environmental impact is the modification of climate due to changes in surface albedo, freshwater fluxes, orography and shifts in vegetation cover. These changes may impact local climate and atmospheric and ocean circulations. For instance, changes in orography alter near-surface temperatures via purely thermodynamical effects and changes in atmospheric circulation. The first feedback (height-feedback) could have been very important for glacial inception (Gallee et al. 1992; Wang and Mysak 2002) and has been evaluated in projections of 
future ice sheet decay (Huybrechts and de Wolde 1999). Changes in the extent of the ice sheet modify the surface albedo and might have been one of the most important feedbacks for glacial inception (Kageyama et al. 2004; Calov et al. 2005). The presence of melting ponds also modifies the surface albedo. Changes in the freshwater fluxes from the ice sheets to the surrounding ocean may modify ocean stratification and the strength of the deep water formation and circulation. For a short review of modelling studies dealing with ice sheet-climate interactions in past climates and under anthropogenic climate change, see, e.g., the introduction of Vizcaíno et al. (2008).

The modification of local climate by changes in the ice sheets could have an impact on the mass balance of ice sheets. This effect has been explicitly evaluated only in very few estimates of future changes in sea level (Ridley et al. 2005; Vizcaíno et al. 2008). The projections of sea level change for the end of the 21st century from the last IPCC report (Table 10.7 of Meehl et al. 2007 and references therein) do not include the effect of ice sheet-climate feedback. However, the study of Ridley et al. (2005) indicates a deceleration of long-term decay rates in the GrIS (negative feedback) associated with the development of local convective cells over Greenland. On the contrary, Vizcaíno et al. (2008) show an acceleration of decay rates in the GrIS due to reduced surface albedo. The effect of these regional climate changes on the mass balance of the ice sheets can be modelled only if the ice sheet component in the climate models is interactively coupled to the rest of components. Besides the model used in this study, only two comprehensive climate models with coupled atmosphereocean general circulation models (AOGCMs) include interactive ice sheets (Ridley et al. 2005; Mikolajewicz et al. 2007a; Vizcaíno et al. 2008). The goal of our study is to evaluate the impact of the inclusion of ice sheets as interactive components of the climate system in the projections of future changes of global ice sheets.

Our study aims to answer three specific questions: (1) what are the expected changes in the ice sheets in response to global warming; (2) how will these changes modify the local and global climate; and (3) how will ice sheet induced climatic changes feed back on the ice sheet mass balance. In order to answer these questions, an earth system model consisting of a coarse-resolution AOGCM, an ice sheet model and a dynamic vegetation model is used. This model was introduced in Mikolajewicz et al. (2007b), where it was applied to the investigation of the impact of increased freshwater fluxes from the Greenland ice sheet to the ocean circulation. In this study the focus will be on the effect of the interactions between ice sheets and climate on the future mass balance of global ice sheets.

A substantial improvement in this model with respect to previous ice sheet-AOGCM coupled models (Ridley et al.
2005; Vizcaíno et al. 2008) is that the calculation of the mass balance of ice sheets is done using the atmospheric forcing-after downscaling-directly, instead of using anomalies relative to the modelled control climate superimposed onto a climatological forcing. Additionally, the model uses an energy balance calculation for the surface mass balance instead of a positive degree-day (PDD) parameterization.

Two approaches are generally used for the calculation of ablation rates. The simpler and most widely used approach is the use of a PDD parameterization. Within this approach, it is assumed that melting is proportional to the annual sum of daily near-surface air temperatures above melting point. The constant of proportionality is calibrated to observed melt in present-day glaciers. An alternative more sophisticated approach is the use of an energy-balance calculation. Both methods can give similar results for present-day surface mass balance with proper tuning (Box et al. 2004), but have different sensitivities to climate forcing (van de Wal 1996). Bougamont et al. (2007) compared the behaviours of a PDD and an energy balance/snowpack model for the calculation of changes in the surface mass balance of the GrIS under a warming climate. They found that the PDD model is more sensitive to climate warming than the energy balance model, generating annual runoff rates almost twice as large for a fixed ice sheet geometry. The modelled snowpack properties evolve with the changing climate, unlike the positive degree day model, which does not include any dependence on changes in lapse rates, specific humidity, winds and cloud cover associated with climate change, and does not include some important albedo feedbacks.

Current coupled ice sheet-climate models applied to anthropogenic climate change studies apply anomaly coupling for the calculation of the mass balance in the ice sheet model (ISM). This represents an important drawback. Due to biases in the simulated present-day climate, the atmospheric fields are not given directly to the ice sheet model. Instead, climate anomalies of climate change scenarios with respect to the control climate are superimposed onto a present-day climatology from observations or reanalysis. The problem of this linear approach arises at non-linear transitions (such as the transition of a significant portion of an ice sheet from non-melt conditions to melt conditions as the climate warms). In these situations the ice sheet and the atmospheric components may not operate in the same climatic range and this can distort the interaction between them.

The goals of the current paper are to describe the coupling between the ice sheet and the other components of the earth system model, and to investigate with this tool the evolution of global ice sheets in response to an idealized anthropogenic greenhouse forcing. Central aspects will be 
the climatic modifications caused by ice sheet changes, and their effect on the mass balance of ice sheets. Section 2 gives a description of the model, with emphasis on the coupling of the ice sheet model to the rest of components and the method for the calculation of the mass balance. In Sect. 3 the spin-up of the model is described, as well as the design of the simulations performed. Section 4 presents the results regarding the evolution of the climate system in response to anthropogenic greenhouse forcing, the changes in ice sheets, the climate modifications caused by these changes, and the effect of local climate changes on the mass balance of the ice sheets. Section 5 gives a summary and conclusions.

\section{Model description}

\subsection{The earth system model}

The components of the earth system model are atmosphere, ocean, sea ice, land vegetation and ice sheets. The model core is the AOGCM ECHAM5/MPI-OM. It does not need flux adjustments and has been tested for applications under present day conditions (Jungclaus et al. 2006). The AOGCM has been used in a higher resolution for the IPCC AR4 simulations of the Max-Planck-Institute for Meteorology. The atmospheric component of the earth system model is the Atmospheric General Circulation Model ECHAM5.2 (Roeckner et al. 2003). In this earth system model it is used with a horizontal resolution of T31 (approx. $3.75^{\circ}$ ) and a vertical resolution of 19 vertical levels on a hybrid sigma-pressure coordinate system. Prognostic variables are vorticity, divergence, surface pressure, temperature, water vapour, cloud water, cloud ice, cloud droplet and ice crystal number concentrations. The prognostic variables, except water and chemical components, are represented by spherical harmonics with triangular truncation at wavenumber 31 . For the advection of water vapour, cloud liquid water, cloud ice and tracer components, a semi-Lagrangian transport scheme (Lin and Rood 1996). The representation of cumulus convection is based on the mass fluxed scheme after Tiedke (1989) with modifications from Nordeng (1994). The cloud microphysics scheme of Lohman and Roeckner (1996) consists of prognostic equations for cloud liquid water and cloud ice. The transfer of solar radiation is parameterised after Fouquart and Bonnel (1980) and the transfer of longwave radiation after Morcrette et al. (1998).

The ocean model MPI-OM (Marsland et al. 2003) is used with a horizontal resolution of $\sim 3^{\circ}$ near the equator on a curvilinear grid with 40 vertical levels. The grid poles are placed on Greenland and Antarctica in order to avoid the pole-singularity problem at the North Pole and in order to obtain higher resolution in the deep-water formation regions of the Labrador Sea, the Greenland Sea, and the Weddell Sea. The topography was interpolated from the ETOPO5 (ETOPO5 1988). Specific topographic features, such as the important conduits of overflows and through flows, were adjusted to observed sill depths. The primitive equations for a hydrostatic Boussinesq fluid are formulated for a free surface. The vertical discretization is on z-levels and the bottom topography is resolved by partial grid cells (Wolff et al. 1997). Scalar and vector variables are arranged on a C-grid (Arakawa and Lamb 1977).

The dynamic and thermodynamic sea ice model is similar to the one in the HOPE model (Wolff et al. 1997) The dynamics of sea ice are formulated using viscous-plastic rheology following Hibler (1979). The changes in sea ice thickness are calculated from the balance of radiative, turbulent, and oceanic heat fluxes and from sea ice advection. The effect of snow accumulation on sea ice is included. The transformation from snow to ice when the snow-ice interface sinks below sea level due to snow loading is modelled. The effect of ice formation and melting is accounted for by assuming a sea ice salinity of 5 psu.

The atmosphere and ocean models are coupled via the OASIS coupler (Valcke et al. 2003). The ocean passes sea surface temperatures, sea ice concentration and thickness, snow depth and ocean surface velocities to the atmosphere. River runoff and glacier calving are treated interactively in the atmosphere model and the freshwater fluxes are given to the ocean as part of the atmospheric freshwater flux field. The land hydrology model includes a river routing scheme (Hagemann and Dümenil-Gates 1998, 2003). This coupling has a time-step of 1 day.

Land vegetation is modelled with the dynamic global vegetation model LPJ (Sitch et al. 2003), which simulates the spatial distribution of ten plant functional types (PFT) over the Earth, with four living biomass and three litter carbon pools defined for each PFT. The presence and type of vegetation influence land surface properties, and thereby the exchange of energy and water. This is modelled using surface albedo, vegetation cover, forest cover and roughness length as in Schurgers et al. (2007), and leaf area index and rooting depth as described in Mikolajewicz et al. (2007b) auxiliary material. The horizontal resolution is the same as for the atmosphere (T31). The model simulates potential vegetation. Anthropogenic effects such as agriculture and deforestation are not included in the model.

The three-dimensional thermomechanical ice sheet model (ISM) SICOPOLIS simulates the ice sheets of both hemispheres. The model is used with a horizontal resolution of $80 \mathrm{~km}$ and 21 vertical levels in the ice domain. The model grid is built on a polar stereographic projection. The model domain is quasi-global, with two sub-domains covering the entire globe except the tropical areas, from 
approximately $20^{\circ} \mathrm{N}$ (S) to the North (South) Pole. The model has been applied to several studies of past, present and future climate (Greve 1997, 2000; Greve et al. 1999; Calov and Marsiat 1998; Savviin et al. 2000).

The ISM integrates the time-dependent equations governing ice sheet extent and thickness, ice velocity, temperature, water content and age for any specific grounded ice as a response to external forcing. This is given by surface temperatures, surface mass balance, sea level and geothermal heat flux.

The model treats ice as an incompressible, heat-conducting, power-law (Glen's law) fluid. Details about the stress-strain relation are given, e.g., in Vizcaíno et al. (2008). No sliding is prescribed if basal ice temperature is lower than pressure melting temperature. If basal ice is at melt temperature, a Weertman-type sliding law (Weertman 1964) is applied. The effect of sediment at the glacier bed is not considered.

The model equations are subjected to the shallow ice approximation (SIA), which means that they are scaled with respect to the ratio of typical thickness to typical length, and only first order terms are kept. The SIA yields hydrostatic pressure conditions and ice flow governed by the gradients of pressure and the shear stresses in horizontal planes. The dynamics of the fast-flowing parts of the ice sheets (ice streams, outlet glaciers, ice shelves) cannot be modelled with this approximation and are not included in this ISM.

In order to allow a moving grounding line despite the lack of ice shelves, ice is allowed to flow behind the grounding line. When the thickness of this "pseudo-floating" ice reaches a critical thickness $H_{c}<200 \mathrm{~m}$, it is lost to the ocean. Also, it is not allowed to flow behind the limits of the continental shelf, whose border is parameterized to be at a certain bedrock depth. Basal and frontal melting rates are prescribed in order to reproduce ocean melting of floating ice. A flotation criterion is used to determine the position of the grounding line.

Isostatic depression and rebound of the lithosphere due to the ice load are modelled by a local lithosphere relaxing asthenosphere model (Le Meur and Huybrechts 1998). For the geothermal heat flux, a global mean value of $55 \mathrm{~mW} \mathrm{~m}^{-2}$ (Sclatter et al. 1980) has been taken, except in Antarctica. A two-dimensional map accounts for the different age of the bedrock in the East and West Antarctic sections, with values of 45 and $70 \mathrm{~mW} \mathrm{~m}^{-2}$, respectively (Sclatter et al. 1980).

The coupling between the atmosphere-ocean and the land vegetation and ice sheet models takes place with a time-step of 1 year. The time step of each model component is $40 \mathrm{~min}$ for the atmosphere, $144 \mathrm{~min}$ for the ocean, and 1 year for the ice sheet model. The land vegetation model runs different processes with different time steps.
Slow processes, e.g., changes in vegetation distribution, run with 1-year time step, while faster processes as carbon cycle processes and phenological changes run on a monthly (e.g., carbon cycle processes) or daily (e.g., photosynthesis) time step.

\subsection{Coupling between the ice sheet model and the earth system model}

The surface mass balance is calculated with a time-step of $6 \mathrm{~h}$ from the output of the previous time step from the atmosphere model. Meltwater fluxes, glacier mask, topography, and changes in sea level due to ice sheet changes are passed from the ISM to the climate model at the end of each simulated year. Sea level changes are added to the orography of the ocean within the atmospheric model.

The atmospheric forcing of the ISM consists of sixhourly radiation (downward shortwave and downward longwave), near-surface and dew-point temperatures, precipitation, wind speed at 10-m height, and surface pressure (used to calculate near-surface air density). The ISM is also forced with sea level changes, which are consistent with the modelled changes in ice sheet mass. These changes modify the position of the grounding line following a flotation criterion.

Given the differences in resolution between the atmospheric and ice sheet models, a downscaling procedure is applied to the atmospheric forcing fields. First, they are bilinearly interpolated from the atmospheric grid onto the ISM grid. To account for the height differences between the topographies of both models, several height corrections have been applied. For near-surface temperature and dew point, a lapse rate of $6.5 \mathrm{~K} \mathrm{~km}^{-1}$ is used. Precipitation rates are corrected from the height-desertification effect, i.e., the reduction of precipitation rates with increasing topographic height, by prescribing a halving of precipitation for each kilometre over a reference height $h_{0}=2,000 \mathrm{~m}$ (Budd and Smith 1979). Therefore, precipitation rates $P_{\text {ISM }}$ at height $h$ in the ISM are derived from precipitation rates from the atmospheric model $P_{\mathrm{GCM}}$ at height $h_{\mathrm{GCM}}$ following

$P_{\mathrm{ISM}}(h)=P_{\mathrm{GCM}}\left\{\begin{array}{l}\exp \left(\gamma_{p}\left[\max \left(h, h_{0}\right)-h_{0}\right]\right) h_{\mathrm{GCM}} \leq h_{0} \\ \exp \left(\gamma_{p}\left[\max \left(h, h_{0}\right)-h_{\mathrm{GCM}}\right]\right) h_{\mathrm{GCM}}>h_{0}\end{array}\right.$

with $\gamma_{\mathrm{p}}=-0.6931 \mathrm{~km}^{-1}$. These parameters used for downscaling of temperature and precipitation fields are standard of SICOPOLIS and have been used in other studies with the model.

For the downward longwave radiation a decrease of $2.9 \mathrm{~W} \mathrm{~m}^{-2}$ is assumed for every $100 \mathrm{~m}$ of height increase (Marty et al. 2002). The near-surface air density is also 
corrected from height changes by calculating the change of near-surface air pressure with height.

The ice sheet model provides freshwater fluxes to the ocean every year. The freshwater flux is given to the ocean at the coastal ocean grid point closest to the ice sheet grid point. Topography and glacier mask are provided from the ice sheet model to the atmospheric model. The glacier mask of the ice sheet model is interpolated onto the atmospheric grid. If more than $40 \%$ of the area of an atmospheric grid point is ice-covered, then the atmospheric grid point is considered as glaciated, otherwise it is completely ice-free.

\subsection{Calculation of surface mass balance}

The surface mass balance is calculated with an energybalance scheme from several six-hourly fields of the atmospheric model. It is calculated at the resolution and surface height of the ice sheet model, from 1-year-output of the atmospheric model. The calculated time-integrated accumulation, surface melting rates and 10-m depth temperature are passed to the ice sheet model, which is run with these boundary conditions. Snowfall rates are derived from precipitation rates with a time step of $6 \mathrm{~h}$. Precipitation is converted into snow whenever near-surface temperatures are lower than $0^{\circ} \mathrm{C}$. Melt rates are calculated from the balance of radiation, latent heat, sensible heat, heat conduction between inner snow layers and the surface layer, and the heat exchanged with the surface due to the fall of precipitation.

A snowpack has been defined and discretised into several layers. Total thickness is $20 \mathrm{~m}$, with an uppermost layer of $0.33 \mathrm{~m}$ and increasing layer thickness with depth. The density and thermal conductivity of the snow vary with depth. The variation of snow thickness with depth, $\rho(z)$, follows the empirical relationship (Schytt 1958)

$\rho(z)=\rho_{\text {ice }}-\left(\rho_{\text {ice }}-\rho_{\text {s }}\right) \times \exp (-C z)$

where $\rho_{\text {ice }}$ is ice density, taken as $917 \mathrm{~kg} \mathrm{~m}^{-3}$ and $C$ is a constant for a given site. The mean value from measurements at two stations in central Greenland, $C=0.024 \mathrm{~m}$ (Paterson 1994), is used.

The thermal conductivity of the snow $K$ is assumed to depend on the snow density through (Schwerdtfeger 1963)

$K(z)=\frac{2 K_{\text {ice }} \rho(z)}{\left(3 \rho_{\text {ice }}-\rho(z)\right)}$

where $K_{\text {ice }}=2.10 \mathrm{~W} \mathrm{~m}^{-1} \mathrm{~K}^{-1}$ (Yen 1981) is the thermal conductivity of ice.

To calculate the melt rates, we first calculate the temperature of the uppermost layer of the snowpack in contact with the atmosphere $T_{\mathrm{s}}$ from the energy balance at the snow surface: $-\rho_{\mathrm{s}} c_{p} \frac{\partial T_{\mathrm{s}}}{\partial t}=\frac{\partial F}{\partial z}$

where $\rho_{\mathrm{s}}$ is the density of the uppermost layer of the snowpack in contact with the atmosphere, $c_{p}$ is the specific heat capacity of snow and $F$ is the sum of the radiative, latent, sensible, precipitation and conduction heat fluxes:

$F=S_{\text {abs }}-L \uparrow+L \downarrow+E+H+H_{P}+H_{\text {cond }}$

$S_{\text {abs }}$ is the absorbed shortwave radiation flux, $L \uparrow$ is the upward longwave radiation, $L \downarrow$ is the downward longwave radiation, $E$ is the latent heat flux, $H$ is the sensible heat flux, $H_{p}$ is the heat either released or lost by precipitation falling on the snow surface, and $H_{\text {cond }}$ is the heat flux conducted from/to the next snow layer. If $T_{\mathrm{s}}$ exceeds the melting temperature $T_{\text {melt }}$, it is set to $T_{\text {melt }}$ for the recalculation of the heat fluxes and Eq. 4 is solved again for $T_{\mathrm{s}}$. The energy needed to warm the surface from the melting point to the new solution for $T_{\mathrm{s}}$ is the energy available for melting. Sublimation rates are calculated from the latent heat fluxes.

The terms of Eq. 5 are calculated as follows. $S_{\text {abs }}$ is calculated from the downward shortwave radiation $S \downarrow$ following

$S_{\mathrm{abs}}=(1-\alpha) \times S \downarrow$

A parameterisation for snow and ice surface albedo $\alpha$ similar to the parameterisation from the atmospheric model, as described in Roeckner et al. (2003), has been used. $\alpha$ varies from $\alpha_{m}=0.55$ when the surface is at melting point and $\alpha_{\max }=0.825$ when $T_{\mathrm{s}}<268.15 \mathrm{~K}$. At intermediate temperatures a linear relationship is applied.

$L \uparrow$ is calculated from the surface snow temperature $T_{\mathrm{s}}$ as the radiation emitted by a black body

$L \uparrow=-\sigma \times T_{\mathrm{s}}^{4}$

with $\sigma=5.67 \times 10^{-8} \mathrm{~W} \mathrm{~m}^{-2} \mathrm{~K}^{-4}$.

$L \downarrow$ is taken from the output of the atmospheric model, after applying interpolation and height-correction.

$H$ is calculated via the bulk-formula

$H=C_{d} \times \rho_{\text {air }} \times u_{10} \times\left(T_{\text {air }}-T_{\mathrm{s}}\right)$

with a drag coefficient $C_{d}=1.515 \mathrm{~J} \mathrm{~kg}^{-1} \mathrm{~K}^{-1}$ (Ambach and Kirchlechner 1986).

$E$ is calculated following Paterson (1994) via the bulkformula

$-L_{v} \times E=22.2 \times A \times u_{10} \times\left(e-e_{\mathrm{s}}\right)$

from the wind speed at $10-\mathrm{m}$ height $u_{10}$, the vapour pressure at screen height $(2 \mathrm{~m}) e$ and at the surface $e_{\mathrm{s}}$ (where the air is assumed to be saturated), the specific latent heat of vaporization $L_{V}$ and $A=1.5 \times 10^{-3}$ (Ambach and Kirchlechner 1986). 
$H_{\text {cond }}$ is calculated from

$H_{\text {cond }}=K \frac{\partial T}{\partial z}$

where $K$ is snow thermal conductivity.

The heat released or absorbed by precipitation falling on the snow surface $H_{p}$ is calculated from the precipitation rates $p$ and the temperature of the raindrops or snowflakes, which is approximated by $T_{\text {air }}$, as

$H_{p}=p \times c_{p} \times\left(T_{\text {air }}-T_{\text {melt }}\right) \times \rho_{w}$

where $\rho_{w}$ is the density of water, and $c_{p}$ is the specific heat capacity of snow or water, depending on the occurrence of precipitation as snow or rain.

The temperature profile in the snow pack is modified every time-step according to the heat fluxes caused by differences of temperature between each layer and the layer immediately above. These temperatures can be modified by the heat released due to refreezing of percolated meltwater. If melting occurs, the surface meltwater can percolate and be refrozen at inner layers of the snow-pack at temperatures lower than the pressure melting point. The potential amount of meltwater that can be refrozen at each layer is calculated from the energy absorbed by the snow layer when its temperature is raised from its initial temperature to $T_{\text {melt }}$. The actual amount of refrozen meltwater at each layer is the minimum of the potential amount that can be refrozen and the amount of meltwater that reaches the layer.

The ice sheet model needs a surface boundary condition for the temperature of the uppermost ice layer of the vertical grid. This is calculated as the annual mean temperature of the snowpack at a depth of $15 \mathrm{~m}$, since daily and seasonal variations of the near-surface air temperature over a glacier propagate approximately only until a snow depth of 10-15 m (Paterson 1994).

\section{Set-up of simulations}

For its spin-up, the ISM was initialisated with a simulation of the last two glacial cycles until year 3000 BP, with a time-dependent signal from the ice cores of GRIP
(Dansgaard et al. 1993) and VOSTOK (Jouzel et al. 1993, 1996) for the northern and southern hemisphere ice sheets, respectively, superimposed to the spatial pattern given by the present-day climatology of ERA40 (Uppala et al. 2005). A linear relationship between temperature and precipitation changes has been used for precipitation forcing (Greve et al. 1999). For sea level forcing the SPECMAP $\delta^{18} O$ record (Imbrie et al. 1984) is used via the conversion (Greve et al. 1999)

$z_{\mathrm{sl}}[\mathrm{m}]=-34.83 \mathrm{~m} \cdot\left(\delta^{18} O[\%]+1.93\right)$

where $z_{\mathrm{s} 1}$ is the sea level expressed in meters.

During this period of the spin-up, melting was calculated following a degree-day scheme as in Vizcaíno et al. (2008). After that, the ice sheet model and the vegetation model were spun-up with the climatology of a control climate simulation from the AOGCM ECHAM5/MPI-OM. In the case of the ISM, this forcing was applied for the period 3000 BP-Present. The surface mass balance was calculated with the same energy-balance scheme that is used in the control and perturbed climate simulations.

After these separate spin-ups of the model components, the coupled model was integrated with and without the ice sheet model for 300 years. From these states all experiments were started. For the control runs the $\mathrm{pCO}_{2}$ was kept at $280 \mathrm{ppmv}$. In the greenhouse simulations, the prescribed atmospheric carbon dioxide concentration was increased by $1 \%$ per year and stabilized at 560 ppmv at year 70 , for the doubling simulations, and at $1,120 \mathrm{ppmv}$ at year 140 , for the quadrupling simulations. All simulations have a length of 600 years.

The total number of simulations is seven. They are listed in Table 1. Three simulations have been performed with the fully-coupled model, corresponding to control (CTRL), doubling $\left(2 \times \mathrm{CO}_{2}\right)$ and quadrupling simulations $\left(4 \times \mathrm{CO}_{2}\right)$. In order to study the effect of changes in the ice sheets on the climate system, three simulations $* \mathrm{~F}$ with fixed ice sheets were performed (CTRLF, $2 \times \mathrm{CO}_{2} \mathrm{~F}, 4 \times \mathrm{CO}_{2} \mathrm{~F}$ ). Freshwater fluxes originating from the ice sheets, orography and glacier mask are kept as prescribed in the atmosphere model and its hydrological subroutine. The comparison of these simulations with the simulations with

Table 1 Description of simulations

\begin{tabular}{ll}
\hline Name & Description \\
\hline $\mathrm{CTRL}$ & Pre-industrial concentration of $\mathrm{CO}_{2}$, kept constant at $280 \mathrm{ppmv}$ \\
$2 \times \mathrm{CO}_{2}$ & $1 \%$ increase of $\mathrm{CO}_{2}$ per year until stabilization at $560 \mathrm{ppmv}$ \\
$4 \times \mathrm{CO}_{2}$ & $1 \%$ increase of $\mathrm{CO}_{2}$ per year until stabilization at $1,120 \mathrm{ppmv}$ \\
$* \mathrm{~F}\left(\mathrm{CTRLF}, 2 \times \mathrm{CO}_{2} \mathrm{~F}\right.$ and $\left.4 \times \mathrm{CO}_{2} \mathrm{~F}\right)$ & $\begin{array}{l}\text { For the rest of model components, ice sheets are kept fixed (fresh water fluxes, } \\
\text { orography and glacier mask prescribed as in the original atmospheric model) }\end{array}$ \\
$* \mathrm{ct}\left(4 \times \mathrm{CO}_{2} \mathrm{ct}\right)$ & For the rest of model components, ice sheets are kept as the interactive ice sheets of CTRL \\
\hline
\end{tabular}


bi-directional coupling of ice sheets and climate permits the identification of climate feedbacks.

An additional simulation $4 \times \mathrm{CO}_{2}$ ct was performed where the ice sheets were passively included, but instead of being prescribed as in the $* \mathrm{~F}$ simulations, they were kept as simulated by the fully-coupled model in CTRL. This was done in order to facilitate a direct identification of the influence of the ice sheets in a warm climate situation, without having to account for the perturbation introduced in the system when the prescribed ice sheets from measurements are replaced by the ice sheets as simulated by the ISM in CTRL.

\section{Results}

\subsection{Control climate over ice sheets and control} ice sheets

The climate simulated by the atmospheric component alone has been compared to observations for different resolutions (Roeckner et al. 2006). The simulated pre-industrial climate of the coupled atmosphere-ocean core (ECHAM5MPIOM) has been analysed in detail and validated against observations (Jungclaus et al. 2006). In the following, we will analyze and validate the climate of the atmospheric model over the ice sheets against observations; as well as the mass balance of the control ice sheets and the simulated ice sheets.

The simulated annual mean temperature of CTRL over the ice sheets is shown in Fig. 1, together with data from the ERA40 reanalysis (Uppala et al. 2005), at $2.5^{\circ} \times 2.5^{\circ}$ resolution, for validation. The simulated temperatures are essentially in agreement with the data from ERA40. The position of the $0^{\circ} \mathrm{C}$ isoline is correct for both ice sheets. The interior of the GrIS shows a warm bias, mostly explained by the smoother topography of the atmospheric model. However, the model has a cold bias in the high elevation zone of East Antarctica. The temperatures at the margins of the AIS, where surface melting is more sensitive to climatic changes, are correct. The simulated annual mean precipitation and temperature of CTRL averaged over the GrIS in the atmospheric grid are $383.2 \mathrm{~mm} \mathrm{year}^{-1}$ and $-18.7^{\circ} \mathrm{C}$, respectively. The averaged accumulation of the different estimates from Church et al. (2001), Table 11.5, is $520 \pm 26 \times 10^{12} \mathrm{~kg} \mathrm{year}^{-1}$, which is equivalent to a mean rate of $304 \pm 15 \mathrm{~mm}$ water equivalent (WE) year $^{-1}$ when averaged over the area of the observed ice sheet. Estimates from Ohmura et al. (1999) are $332 \mathrm{~mm} \mathrm{WE}$ year $^{-1}$. It must be noted that the given mean temperature and precipitation rate are calculated at the height of the surface of the atmosphere model. When interpolated to the finer ISM grid-following a constant
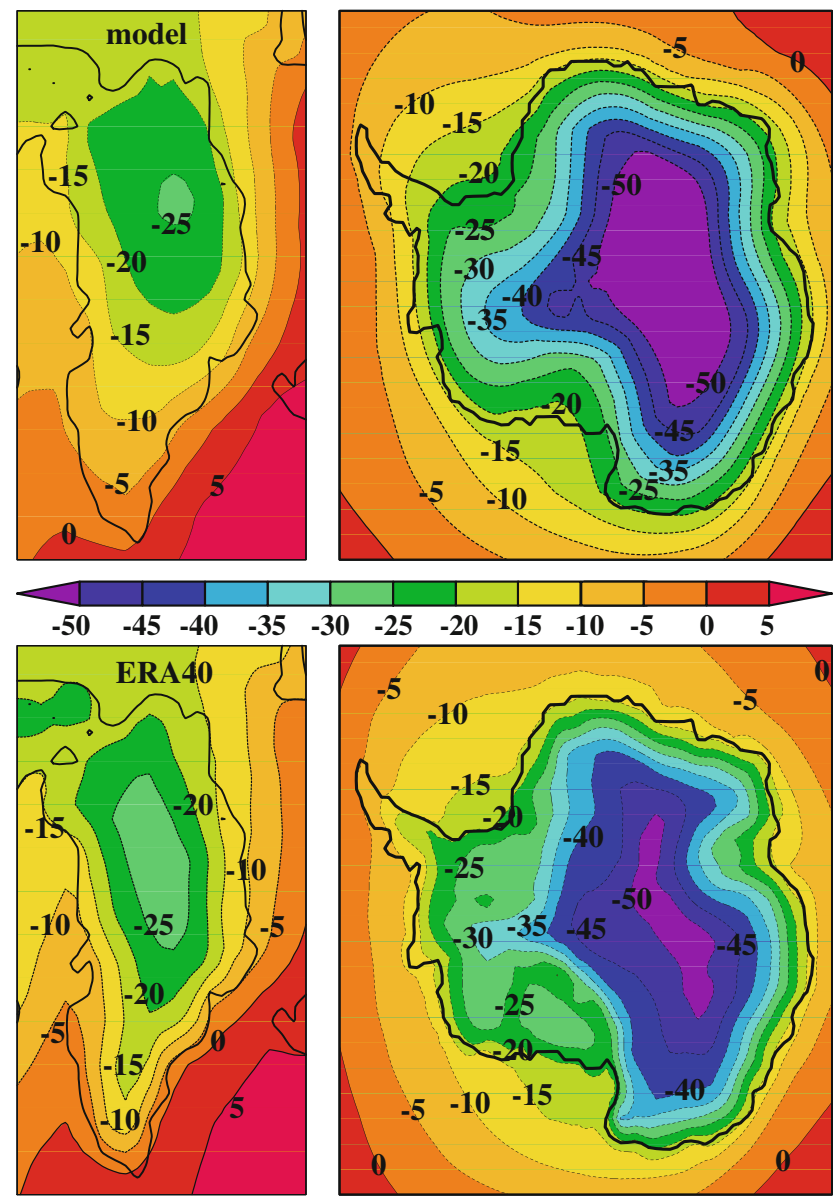

Fig. 1 Comparison of annual mean near-surface air temperatures $\left({ }^{\circ} \mathrm{C}\right)$ over Greenland and Antarctica in CTRL and years 1957-2002 from ERA40

lapse rate of $6.5^{\circ} \mathrm{C} \mathrm{km}^{-1}$ for temperatures and Eq. 1 for precipitation-precipitation rates and temperatures are reduced due to the less smoothed topography of the ISM. For the AIS, the simulated annual mean precipitation and temperature are $183.0 \mathrm{~mm}$ year ${ }^{-1}$ and $-37.2^{\circ} \mathrm{C}$, respectively. The observed mean accumulation over grounded ice is $149 \pm 6 \mathrm{~mm} \mathrm{WE}$ year $^{-1}$, obtained considering the total accumulation rate and area of grounded ice given in Church et al. 2001, Tables 11.6 and 11.3. This accumulation rate is the mean of the estimates from the studies referenced in Table 11.6.

The simulated areas in the atmospheric grid for the GrIS and the AIS are 2.13 and $13.55 \times 10^{6} \mathrm{~km}^{2}$, respectively. The areas given in Church et al. (2001), Table 11.3, are 1.71 and $12.37 \times 10^{6} \mathrm{~km}^{2}$. The simulated area in the ISM grid of northern hemisphere ice sheets is $2.54 \pm 0.04 \times$ $10^{6} \mathrm{~km}^{2}$. Most of the simulated ice sheets and ice caps (93\% of a total volume of $9.35 \pm 0.01 \mathrm{~m}$ sea level equivalent, SLE) correspond to Greenland. Other glaciated areas are placed on the Canadian Archipelago (Baffin Island, Ellesmere Island), in the Rocky Mountains, the 
Alaskan Range, and on high-elevated areas of East Siberia, Svalbard and Novaya Zemlya. These areas correspond to the location of actual glaciers and ice caps (see e.g., Fig. 1. from Raper and Braithwaite 2006). The relative high variability in the area of northern hemisphere ice sheets is due to retreat and advance of the Canadian and Siberian ice caps.

The volume of the simulated GrIS from CTRL is $8.73 \pm 0.02 \mathrm{~m}$ SLE, which exceeds observational estimates by $21 \%$ (Church et al. 2001, Table 11.3, and references therein). The biggest differences between modelled and observed topographies exceed $500 \mathrm{~m}$ and are located in northeast Greenland (Fig. 2). At the margin of this area, the ice sheet is occupying a space that is currently ocean. At the west, the simulated ice thickness is lower than observed by $300-500 \mathrm{~m}$.

The time-mean volume of the simulated AIS from CTRL is $67.08 \mathrm{~m} \mathrm{SLE}$, which exceeds observational estimates by $10 \%$ (Church et al. 2001, Table 11.3), due to overestimation of ice thickness in the Antarctic Peninsula, Amundsen Coast, Siple Coast and the drainage area of the Amery Shelf (Fig. 2). The simulated ice sheet does not include any ice shelves.

The different terms of the mass budget of the GrIS are close to a perfect balance ( $-2 \mathrm{Gt}_{\text {year }}{ }^{-1}$, see Table 2 ). Modelled and observational accumulation rates are 725 and $520 \mathrm{Gt} \mathrm{year}^{-1}$, respectively. This overestimation has two sources: the overestimation of precipitation in the atmospheric model, which was explained before, and the bigger area of the modelled ice sheet. Observations indicate that surface melting represents approximately half of the total mass losses of the GrIS. In our model, $235 \mathrm{Gt}^{\text {year }}{ }^{-1}$ are lost as surface melting over grounded ice. This represents less than half of total ablation. The rest of ice is lost at the bottom due to geothermal heat fluxes $\left(17 \mathrm{Gt} \mathrm{year}^{-1}\right)$ and behind the grounding line, which would be equivalent to iceberg calving. The position of the equilibrium line in the simulated GrIS is approximately correct (Fig. 3). The equilibrium line defines the limit between the ablation area, with negative surface mass balance, and the accumulation area, with positive surface mass balance. The gradient of snowfall rates over the GrIS are well captured by the model, being highest at southwestern Greenland and lowest in the interior and towards the northwest (compare Fig. 3 with, e.g., Fig. 2c of Huybrechts et al. 2004 and references therein). The main biases of the simulated snowfall are the overestimation of rates in the North-East, where the topography was shown to be biased as well (Fig. 3), and underestimation in the south-east, where the coarse resolution of the model does not permit to resolve the very steep topographic gradient, and therefore the local maxima of precipitation. Modelled surface melting is constrained to the margins of the ice sheet. When compared with maps of
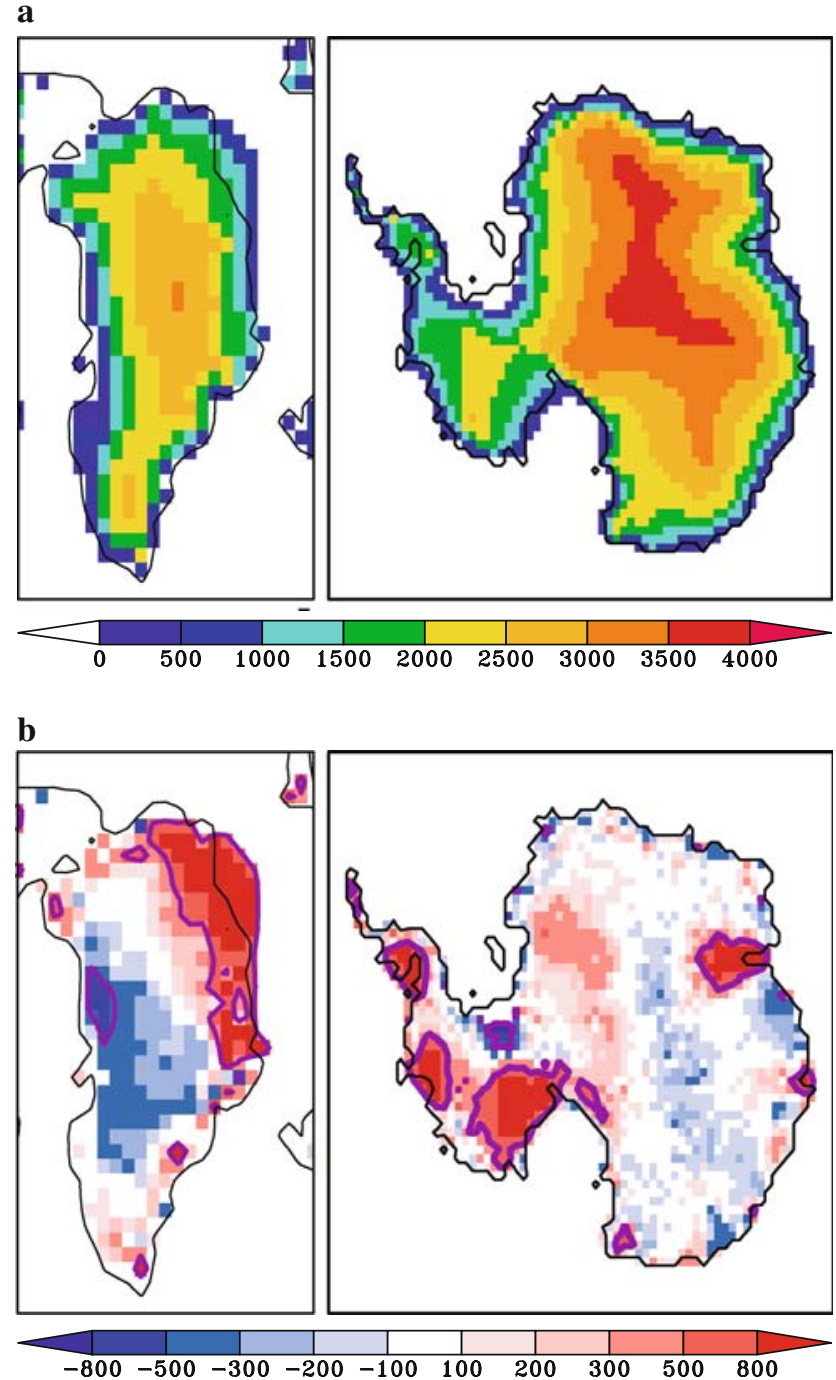

Fig. 2 a Topography of CTRL ice sheets and $\mathbf{b}$ anomalies with ETOPO5 $(\mathrm{m})$ in the ice sheet model grid. The purple contour line indicates anomalies exceeding $500 \mathrm{~m}$ in magnitude. The black contour line indicates is the zero isoline of CTRL topography in the ice sheet model

surface melting from satellite data of the last decades of the 20th century (see, e.g., the 1979-1994 composite of melt in Fig. 5 of Abdalati and Steffen 1997, or the extent of melt in individual years between 1995 and 2005 in Fig. 3 of Mernild et al. 2008, which presents CIRES data), the model shows similar areas of surface melting. However, it fails to reproduce the occurrence at some years of extensive melting over the high elevation areas of the South. While a direct comparison between model and satellite data is not possible due to the fact that the modelled control ice sheets correspond to pre-industrial climate, the bias might be explained as well by two causes. The first is a cold bias in the North Atlantic caused by underestimation of heat transport by the ocean due to resolution limitation. The 
Table 2 Mass balance of the Greenland ice sheet

Unless otherwise specified, numbers refer to all points with ice velocity different from zero in the ice sheet model. When "grounded ice" is specified, only grounded areas have been included. Units are Gt year ${ }^{-1}$. Note that "imbalance" refers to the whole ice sheet, including non-grounded ice

$\begin{array}{lll}\begin{array}{l}\text { Control ice sheet, } \\ \text { average years 500-600 }\end{array} & \begin{array}{l}\text { Reeh } \\ \text { et al. (1999) }\end{array} & \begin{array}{l}\text { Mean and standard deviation } \\ \text { of the studies shown in TAR, } \\ \text { Table 11.5 (Church et al. 2001) }\end{array} \\ 725 & 547 & 520 \pm 26 \\ 235 & 276 & 297 \pm 32 \\ 783 & & \\ 77 & 235 & 235 \pm 33 \\ 785(-2) & 32 & 32 \pm 3\end{array}$

second is the overestimation of the lapse rate over melting surfaces in the downscaling of the atmospheric forcing to the ice sheet model. The later problem will be explained in detail in Sect. 4.5 and in the conclusions.

The mass budget of the modelled AIS suffers from a relatively large imbalance between gains and losses $\left(+245 \mathrm{Gt}\right.$ year $\left.^{-1}\right)$, caused by overestimation of precipitation (Table 3). The modelled accumulation rate is $2,447 \mathrm{Gt}$ year $^{-1}$, which exceeds a recent estimate (van de Berg et al. 2006 ) by 18 to $24 \%$. The sources of this overestimation are the same as for the GrIS. The simulated runoff is very close to present-day estimations, with very low values $(+86 \mathrm{Gt}$ year $^{-1}$ ). The modelled equilibrium line coincides approximately with the grounding line (Fig. 3). This is consistent with the current state of the AIS, where most of ice is ablated via calving and ocean melting. The large-scale map of snowfall agrees in general with observations (compare Fig. 3 with, e.g., Fig. 1c of Huybrechts et al. 2004 and references therein). Among the main local biases, there is underestimation of snowfall over the area of the Amundsen Sea Embayment. Modelled surface melting only takes place at some locations at the margins of the ice sheet.

The simulated ice sheets compare relatively well with observations, given the low resolution of the ice sheet and atmospheric models. The modelled GrIS is approximately in balance and has correct ablation gradients, which yields a stable control ice sheet that can serve well as reference for the forced simulations of anthropogenic climate change. In the case of the AIS, there is a non-negligible imbalance of ablation and accumulation. However, the ablation gradients and the position of the equilibrium line are correct. Also, the mentioned imbalance is small compared with the magnitude of the response to global warming, as it will be shown in the analysis of the greenhouse simulations (4.3). In summary, the modelled ice sheets of the control simulation are stable enough to serve as reference for the greenhouse simulations. The magnitude and distribution of mass balance terms compare sufficiently well with presentday observations as to guarantee that the response to greenhouse forcing will not be affected by critical biases in the initial state. In addition, the absence of fundamental biases in the modelled climate enables a direct coupling with the ISM, avoiding the use of anomalies. This will guarantee consistent responses to external forcing across the different model components, including the ice sheets, as well as increased confidence in the representation of feedbacks. The major limitation of our model set-up is the under-representation of ice dynamics. The response of fastflowing parts of the ice sheets (ice streams, outlet glaciers, ice shelves) to global warming cannot be captured with our model.

\subsection{Climate change}

During the phase of exponential increase of carbon dioxide concentrations, the global mean temperature increases at an approximately constant rate, which is consistent with a linear increase in radiative forcing. At the time when the atmospheric $\mathrm{pCO}_{2}$ has increased to double $\left(2 \times \mathrm{CO}_{2}\right.$, year 70) and four times $\left(4 \times \mathrm{CO}_{2}\right.$, year 140) its pre-industrial level, the increase in global mean temperature is 2 and $5.5 \mathrm{~K}$, respectively. After stabilisation of carbon dioxide concentrations, the positive trend of global mean temperatures decreases. By year 600, the global mean near-surface air temperature anomaly is $8.5 \mathrm{~K}$ in $4 \times \mathrm{CO}_{2}$ and $4 \mathrm{~K}$ in $2 \times \mathrm{CO}_{2}$ (Fig. $4 \mathrm{a}$ ), and has still a rising trend. A similar evolution of global mean temperature can be seen in the simulations $* \mathrm{~F}$ and $* \mathrm{ct}$ not including interactive ice sheets, indicating that changes in the ice sheets do not affect air temperatures at a global scale. The simulated warming is stronger at high latitudes and arid regions (Fig. 5a, b). In $2 \times \mathrm{CO}_{2}$ the Arctic becomes seasonally ice-free, while in $4 \times \mathrm{CO}_{2}$ the Arctic is ice-free year-around. Changes in the annual mean temperature in most of the Arctic are higher than $18 \mathrm{~K}$ by the end of $4 \times \mathrm{CO}_{2}$.

Increases of more than $14 \mathrm{~K}$ in annual mean temperatures are simulated in most of the Arctic, in Alaska, northern Siberia and the interior of Antarctica and in the Ross Sea by the end of $4 \times \mathrm{CO}_{2}$. Increases of more than $11 \mathrm{~K}$ take place all over Antarctica and in the northern half of Greenland. No warming or small warming is simulated in the northern North Atlantic, due to decreased ocean heat 


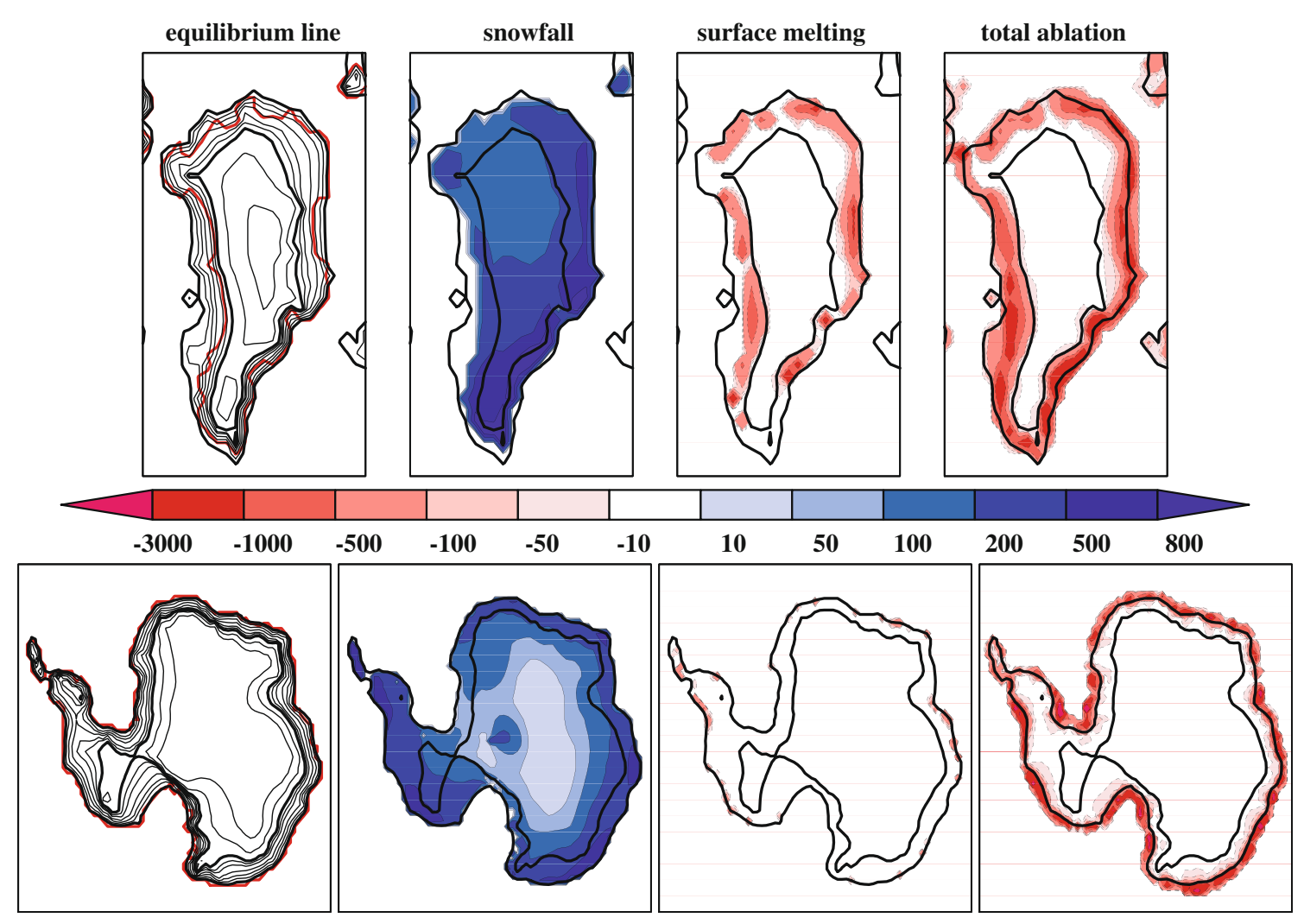

Fig. 3 Mass balance (mm WE year ${ }^{-1}$ ) of simulated pre-industrial ice sheets. In the first plot, the equilibrium line is plotted in red against a map of simulated topography (contour lines every $400 \mathrm{~m}$ ). The thick black lines in all plots indicate the isolines of 0 and 2,000 m surface elevation. The second to fourth plots of each ice sheet represent snowfall, surface melting and total ablation. Positive (negative) numbers indicate mass gain (loss)
Table 3 As Table 2, for the Antarctic ice sheet

\begin{tabular}{|c|c|c|c|}
\hline & $\begin{array}{l}\text { Control ice sheet, } \\
\text { average years } \\
500-600\end{array}$ & $\begin{array}{l}\text { van de Berg } \\
\text { et al. (2006) }\end{array}$ & $\begin{array}{l}\text { Mean and standard deviation of } \\
\text { the studies shown in TAR, } \\
\text { Table 11.6 (Church et al. 2001) }\end{array}$ \\
\hline Accumulation, grounded ice & 2,447 & $1,811-2,076$ & $1,843 \pm 76$ \\
\hline Runoff, grounded ice & 86 & & $10 \pm 10$ \\
\hline Accumulation & 2,800 & & $2,246 \pm 86$ \\
\hline Iceberg production & & & $2,072 \pm 304$ \\
\hline Ice shelf melting & & & $540 \pm 218$ \\
\hline Bottom melting, grounded ice & 71 & & \\
\hline Total ablation (and imbalance) & $2,555(245)$ & & \\
\hline
\end{tabular}

transport by a weakened North Atlantic meridional overturning circulation (NAMOC) (Fig. 4b).

The NAMOC weakens in all greenhouse simulations from its CTRL value of $14 \mathrm{~Sv}\left(1 \mathrm{~Sv}=10^{6} \mathrm{~m}^{3} \mathrm{~s}^{-1}\right)$ at $40^{\circ} \mathrm{N}$ and at $1,040 \mathrm{~m}$ depth (Fig. 4b). By year 100, the strength of the overturning is $8 \mathrm{~Sv}$. 50 years later the NAMOC in $2 \times \mathrm{CO}_{2}$ has weakened to approximately $6 \mathrm{~Sv}$ and remains at this level until year 600 . In $4 \times \mathrm{CO}_{2}$, the NAMOC continues weakening until year 250, when it reaches a minimum of $2.5 \mathrm{~Sv}$. This level is kept until the end of the simulation. This weakening of the NAMOC is caused by surface warming and higher freshwater fluxes into the North Atlantic and Arctic (Fig. 4c). The contribution of meltwater from the GrIS to these positive freshwater anomalies and to NAMOC changes will be analysed in Sect. 4.4.1.

Boreal forests expand towards the Arctic coast (Fig. 4d). From a $40 \%$ forest-covered land north of $60^{\circ} \mathrm{N}$ in CTRL, this fraction increases to $50 \%\left(2 \times \mathrm{CO}_{2}\right)$ and $70 \%$ $\left(4 \times \mathrm{CO}_{2}\right)$ by year 200 . Boreal forests appear also in parts of western Greenland. This expansion enhances high-latitude warming via darker background albedos and stronger 
Fig. 4 Time series of CTRL (black), CTRLF (green), $2 \times \mathrm{CO}_{2}$ (dark blue), $2 \times \mathrm{CO}_{2} \mathrm{~F}$ (light blue), $4 \times \mathrm{CO}_{2}$ (red), $4 \times \mathrm{CO}_{2} \mathrm{~F}$ (orange), $4 \times \mathrm{CO}_{2} \mathrm{ct}$ (maroon): a near-surface global-mean air temperature anomaly, b strength of NAMOC at $40^{\circ} \mathrm{N}$ and $1,050 \mathrm{~m}$ depth (Sv), c total net fresh-water fluxes into the North Atlantic and Arctic (Sv), d forest fraction between $60^{\circ} \mathrm{N}$ and $90^{\circ} \mathrm{N}$. Plotted are annual mean values (thin) and running means over 20 years (thick)
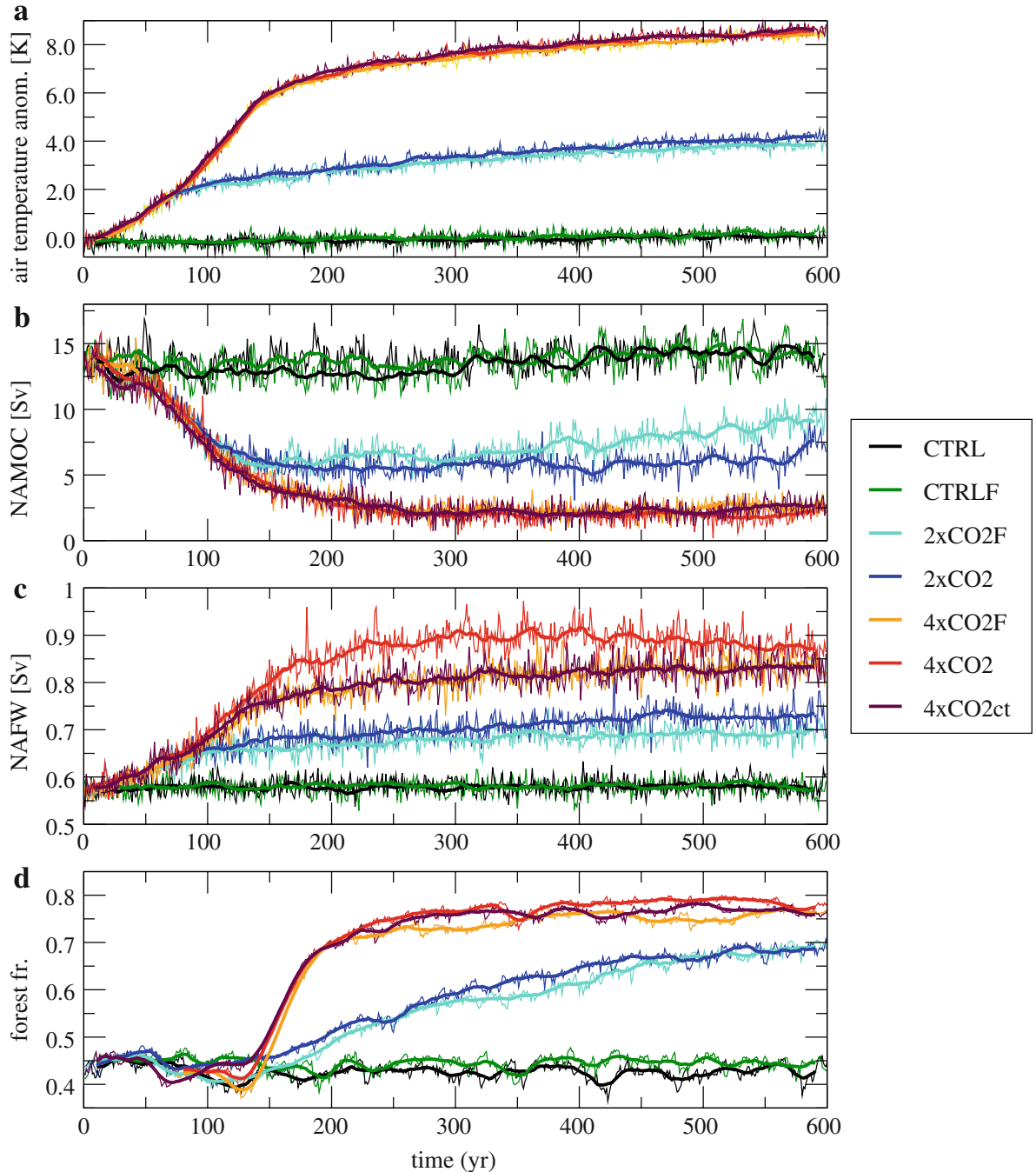

masking of snow cover by trees during spring and early summer.

Global mean precipitation rates at the time of carbon stabilization increase by $3 \%$ in $2 \times \mathrm{CO}_{2}$ and $9 \%$ in $4 \times \mathrm{CO}_{2}$, respectively. The respective precipitation rates increase 9 and $17 \%$ at the end of the simulations. Most subtropical regions become drier, while the rest of the globe, including the areas occupied by the ice sheets, experiences increased precipitation (Fig. 5c).

\subsection{Evolution of ice sheets}

In this section, the simulated evolution of the ice sheets of Greenland and Antarctica under doubling and quadrupling scenarios with the fully coupled model will be analysed. Since our model does not simulate either ice shelves nor ice streams and other fast-flow components of ice sheets, our projections lack the contribution of fast dynamical changes. However, recent observations (Joughin et al. 2003; Scambos et al. 2004; Rignot and Kanagaratnam 2006;
Shepherd and Wingham 2007) indicate that these dynamical changes are the main drivers of current mass balance change and might be also be the main drivers of future change. Therefore, our projections should be taken as a lowend estimate of the contribution of the ice sheets to future sea level rise. Extreme caution should be applied in the interpretation of the results for the AIS, where most of the ablation currently takes place beyond the grounding line.

\subsubsection{Greenland ice sheet (GrIS)}

The simulated anomalies of annual near-surface temperature increase with latitude over Greenland. In $4 \times \mathrm{CO}_{2}$ they range from 1 to $3 \mathrm{~K}$ in the southern part of the island to more than $14 \mathrm{~K}$ at the northern coast (Fig. 5b). This strong gradient, also found in $2 \times \mathrm{CO}_{2}$ (Fig. 5a), is explained by two factors: the higher warming simulated over the Arctic and high latitudes, caused mainly by sea ice demise, and the reduced warming in the North Atlantic southeast of Greenland caused by reduced ocean heat transport as 
Fig. 5 Global near-surface air temperature $(\mathrm{K})$ and precipitation $\left(\mathrm{mm} \mathrm{year}^{-1}\right)$ anomalies respect to CTRL: a temperature from $2 \times \mathrm{CO}_{2}$; b temperature from $4 \times \mathrm{CO}_{2}$; and $\mathbf{c}$ precipitation in $4 \times \mathrm{CO}_{2}$. Displayed is a mean over years 501-600 of each experiment

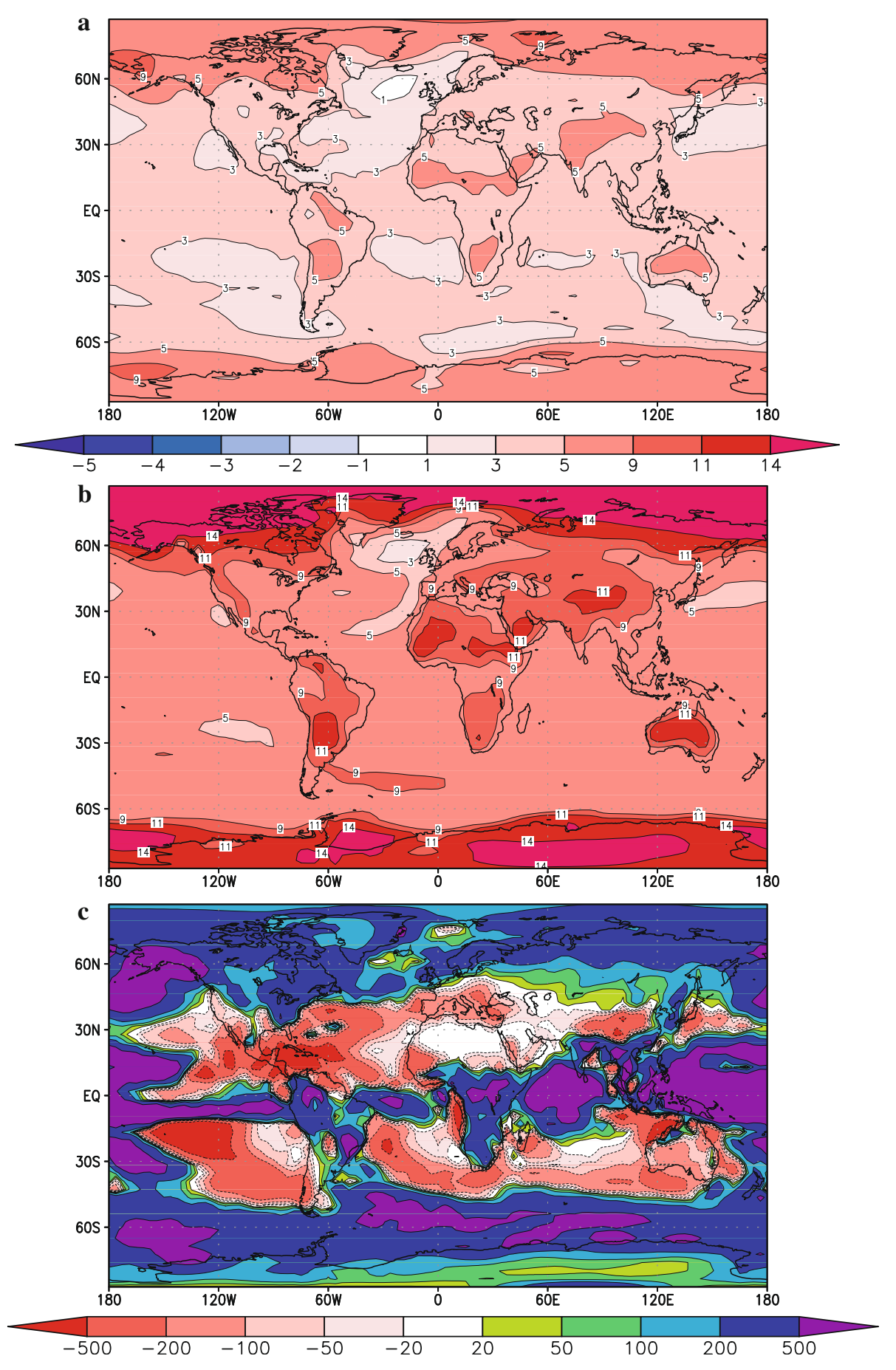

consequence of a weakened NAMOC. Ridley et al. (2005) also show enhanced warming in the north caused by sea ice changes. The local changes in near-surface temperature by the end of the simulations indicate that winter anomalies (not shown) are stronger than summer anomalies (Fig. 6). In $2 \times \mathrm{CO}_{2}$ and averaged over the summer seasons of years $501-600$, the northern half of the island is 5-9 $\mathrm{K}$ warmer than in CTRL and the changes are less than $1 \mathrm{~K}$ in magnitude in the southern tip. In $4 \times \mathrm{CO}_{2}$, the anomalies are highest in the northern interior of the ice sheet, due to maximum reduction of height with respect to CTRL, and in two grid points at the northwest, with anomalies of more than $14 \mathrm{~K}$, where the ice sheet has retreated.

The GrIS decays in both greenhouse simulations (Fig. 7). By year 600, the northern hemisphere ice sheets have lost 1.03 and $3.38 \mathrm{~m}$ SLE. By year 600, the GrIS has lost 0.98 and $3.04 \mathrm{~m} \mathrm{SLE}$, which are equivalent to $11 \%$ of the initial volume in $2 \times \mathrm{CO}_{2}$ and $35 \%$. In $4 \times \mathrm{CO}_{2}$, decay 
rates decelerate from year 400 . The area of northern hemisphere ice sheets decays from an original area of $2.54 \times 10^{6} \mathrm{~km}^{2}$ to $2.25\left(2 \times \mathrm{CO}_{2}\right)$ and $1.7 \times 10^{6} \mathrm{~km}^{2}$ $\left(4 \times \mathrm{CO}_{2}\right)$, which represent decreases of 12 and $33 \%$.

In $2 \times \mathrm{CO}_{2}$, most of the retreat of the ice sheet takes place in the east margin (Fig. 8). Changes in ice thickness are negative in most of the areas at the margin of the ice sheet. Only some areas, mostly in the interior, experience an increase in thickness. In $4 \times \mathrm{CO}_{2}$, the ice sheet retreats along most of the margins north of $70^{\circ} \mathrm{N}$. The strongest retreat takes place in the mid-east and north-east margins. At very few grid points an increase in ice thickness is simulated. At the new margins, thickness has decreased by more than $500 \mathrm{~m}$, and between 200 and $500 \mathrm{~m}$ in most of the interior. The region with the smallest changes is the southernmost third of the ice sheet, consistently with the smallest regional change of temperature in this region (Fig. 5a, b), that has been explained at the beginning of this section.
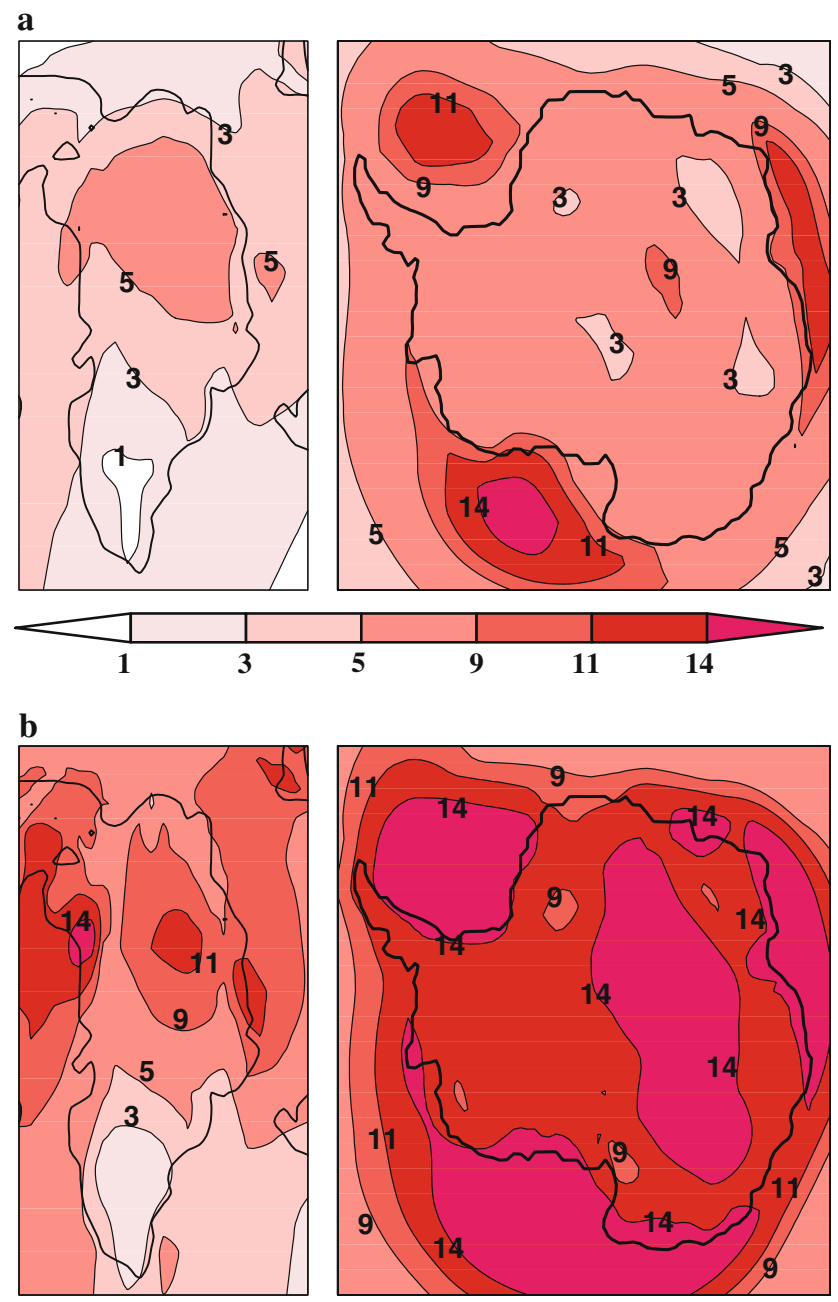

Fig. 6 Summer (JJA) near-surface temperature change $(\mathrm{K})$ in Greenland and Antarctica for (a) $2 \times \mathrm{CO}_{2}$ and (b) $4 \times \mathrm{CO}_{2}$ averaged over years $501-600$
Ablation rates in the northern hemisphere ice sheets increase in $2 \times \mathrm{CO}_{2}$ during the phase of increasing $\mathrm{pCO}_{2}$ by

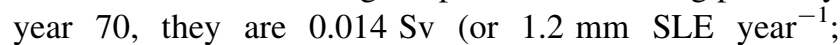
$1 \mathrm{~Sv}=87.2 \mathrm{~mm} \mathrm{SLE} \mathrm{year}^{-1}$ ) higher than in CTRL. From then, ablation rates increase continuously at a slower pace, until $0.025 \mathrm{~Sv}$ ( $\left.2.5 \mathrm{~mm} \mathrm{SLE} \mathrm{year}{ }^{-1}\right)$ by year 600 . In $4 \times \mathrm{CO}_{2}$ melting rates increase until year 200 , when the melting is $0.1 \mathrm{~Sv}\left(8.7 \mathrm{~mm} \mathrm{SLE} \mathrm{year}{ }^{-1}\right)$ higher than in CTRL. This melting rate is kept until year 400. From then, it decays to $0.06 \mathrm{~Sv}$ ( $4.6 \mathrm{~mm} \mathrm{SLE} \mathrm{year}{ }^{-1}$ ) by year 600 . The total accumulation rate is similar in $2 \times \mathrm{CO}_{2}$ and in CTRL during the first 400 years. From year 400, rates are slightly lower than in CTRL, regardless of the higher precipitation rates. This is due to the combined effect of an increased fraction of precipitation falling as rain due to higher temperatures and of the reduced area of the ice sheets. In $4 \times \mathrm{CO}_{2}$, accumulation rates are similar to CTRL until year 150 , and decrease thereafter. This can be explained by the stronger decay rate of ice sheet area.

In $2 \times \mathrm{CO}_{2}$, all areas at elevations lower than $2,000 \mathrm{~m}$ experience summer melting by year 600 . In addition, half of the area with elevations higher than 2,000 m shows melting rates between 100 and $500 \mathrm{~mm}$ WE year $^{-1}$ (Fig. 9). In large areas of the northern half of the eastern and western margins melting rate increases are between 1 and $3 \mathrm{~m} \mathrm{WE}$ year $^{-1}$. Higher topographic gradients due to reduced thickness in the margins produce increased ice flux from the interior to the margins. Snowfall increases over most of the ice sheet, except some areas at the coast where the warm temperatures decrease the rate of precipitation falling as snow. Increases between 10 and $50 \mathrm{~mm} \mathrm{WE}$ year $^{-1}$ take place in the northeast of the ice sheet, which is the driest region. In the rest of the ice sheet, increases range generally between 50 and $100 \mathrm{~mm}$ WE year ${ }^{-1}$.

In $4 \times \mathrm{CO}_{2}$, almost all the ice sheet except the southern summit region experience surface melting by year 600 (Fig. 9). In approximately half of the areas higher than $2,000 \mathrm{~m}$, melting rates increase between 500 and $1,000 \mathrm{~mm}$ WE year ${ }^{-1}$. In most of the areas lower than $2,000 \mathrm{~m}$, melting rate increases are within the range of 1-3 m year ${ }^{-1}$. In most of the ice sheet accumulation rates increase by more than $100 \mathrm{~mm}_{\text {year }}{ }^{-1}$. The changes in local mass balance are clearly dominated by changes in surface melting almost everywhere.

\subsubsection{Antarctic ice sheet (AIS)}

Due to the imbalance between accumulation and ablation described in Sect. 4.1, the simulated AIS from CTRL is not in equilibrium and its volume grows at a rate of $0.63 \mathrm{~mm}$ SLE year ${ }^{-1}$ (Fig. 7). The volume of the AIS slightly increases with time in $2 \times \mathrm{CO}_{2}$. By the end of the 
simulation, it has increased by $0.15 \mathrm{~m}$ SLE with respect to the volume of CTRL at this time. This represents an increase of $0.2 \%$ with respect to CTRL. However, the total area of the ice sheet shrinks. By the end of the simulation, $0.25 \times 10^{6} \mathrm{~km}^{2}$ of grounded ice have been lost. In $4 \times \mathrm{CO}_{2}$ the ice sheet begins to lose mass from year 150 . By year 600 , it has lost $1.63 \mathrm{~m}$ SLE. Approximately $85 \%$ of the volume loss takes place in West Antarctica. The area of the ice sheet is reduced by $1.0 \times 10^{6} \mathrm{~km}^{2}$.

The total ablation rate increases steadily in $2 \times \mathrm{CO}_{2}$ from year 0 to approximately year 120 , when it is $0.02 \mathrm{~Sv}$ (1.6 mm SLE year ${ }^{-1}$ ) higher than in CTRL. From then, the increase is much smoother. Total accumulation follows a similar behaviour, with a smoother increase from year 120 . In $4 \times \mathrm{CO}_{2}$, total ablation increases at a fast pace until year 160 , when it is $0.09 \mathrm{~Sv}$ (7.6 mm SLE year ${ }^{-1}$ ) higher than in CTRL. From then and until year 600 , it only increases by additional $0.02 \mathrm{~Sv}$. Total accumulation increases by almost $50 \%$ with respect to CTRL by year 160 , and increases very slightly after that.

In both $2 \times \mathrm{CO}_{2}$ and $4 \times \mathrm{CO}_{2}$, ice thickness decreases in part of the margins of the ice sheet and increases in most of
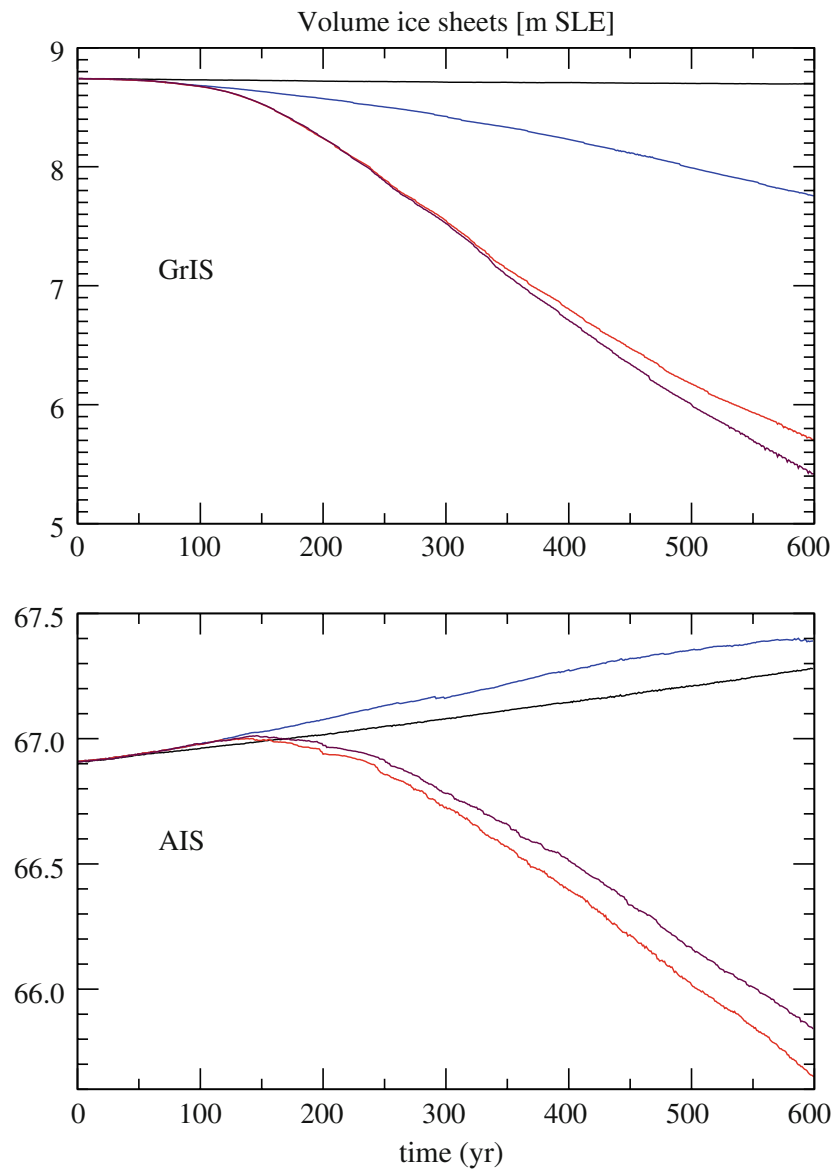

Fig. 7 Changes in the volume of the GrIS and the AIS (m SLE) in CTRL (black), $2 \times \mathrm{CO}_{2}$ (blue), $4 \times \mathrm{CO}_{2}$ (red) and $4 \times \mathrm{CO}_{2}$ ct (maroon) the interior (Fig. 8). Most of ice is lost in the Antarctic Peninsula, coast of the Amundsen Sea, Siple Coast, and a vast area surrounding and including the drainage area of Lambert Glacier. In $2 \times \mathrm{CO}_{2}$, thickness changes at the highest area in East Antarctica are less than $10 \mathrm{~m}$ by year 600. In most of the rest of the interior of Antarctica, ice thickness increases by $10-50 \mathrm{~m}$. In $4 \times \mathrm{CO}_{2}$, the ice sheet retreats almost everywhere at coastal locations. In a substantial part of the Antarctic Peninsula, the coast of the Amundsen Sea, and the area around Lambert glacier, thickness changes between 200 and $500 \mathrm{~m}$. In the interior of East Antarctica, the thickness increases in $4 \times \mathrm{CO}_{2}$ are approximately double those in $2 \times \mathrm{CO}_{2}$. In the lowest areas of the interior, thickness increases by more than $50 \mathrm{~m}$.

By the end of $2 \times \mathrm{CO}_{2}$, many coastal areas at heights lower than 2,000 $\mathrm{m}$ have begun to melt (Fig. 10). By the end of $4 \times \mathrm{CO}_{2}$, most of the areas below 2,000 m experience melting, with higher rates in the areas closer to the sea. Accumulation rates are higher everywhere in both simulations, with increases of $10-50 \mathrm{~mm} \mathrm{year}^{-1}$ in most of Antarctica in $2 \times \mathrm{CO}_{2}$. In $4 \times \mathrm{CO}_{2}$, accumulation increases

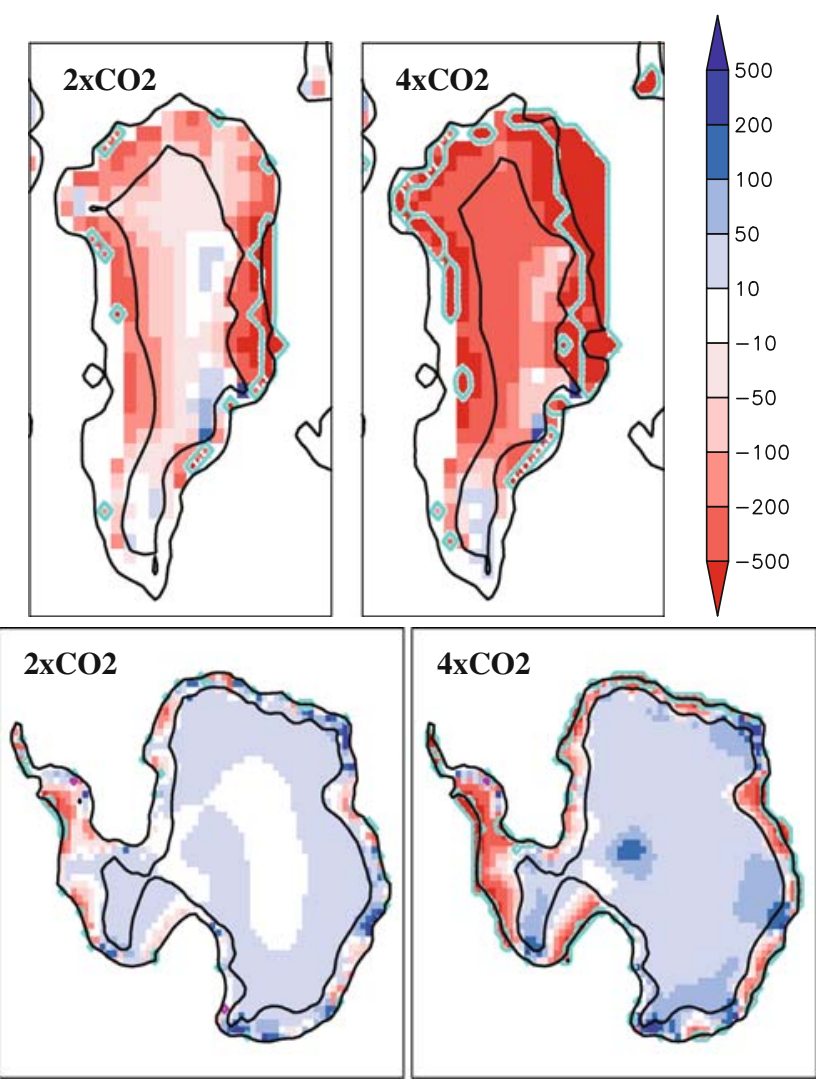

Fig. 8 Ice thickness change of the GrIS and AIS (m). Anomalies correspond to years 501-600 minus the same years of CTRL. The light blue (pink) line delimits areas where the ice sheet has retreated (advanced). The thick black lines indicate the isolines of 0 and 2,000 m surface elevation 
Fig. 9 Changes in mass balance components $\left(\mathrm{mm}\right.$ year $\left.{ }^{-1}\right)$ of the GrIS (total, accumulation, surface melting, and transport) for $2 \times \mathrm{CO}_{2}$ and $4 \times \mathrm{CO}_{2}$ with respect to CTRL. Averaged period: years 501600. Positive terms (in blue) indicate gain of mass. The thick black lines indicate the isolines of 0 and 2,000 $\mathrm{m}$ surface elevation

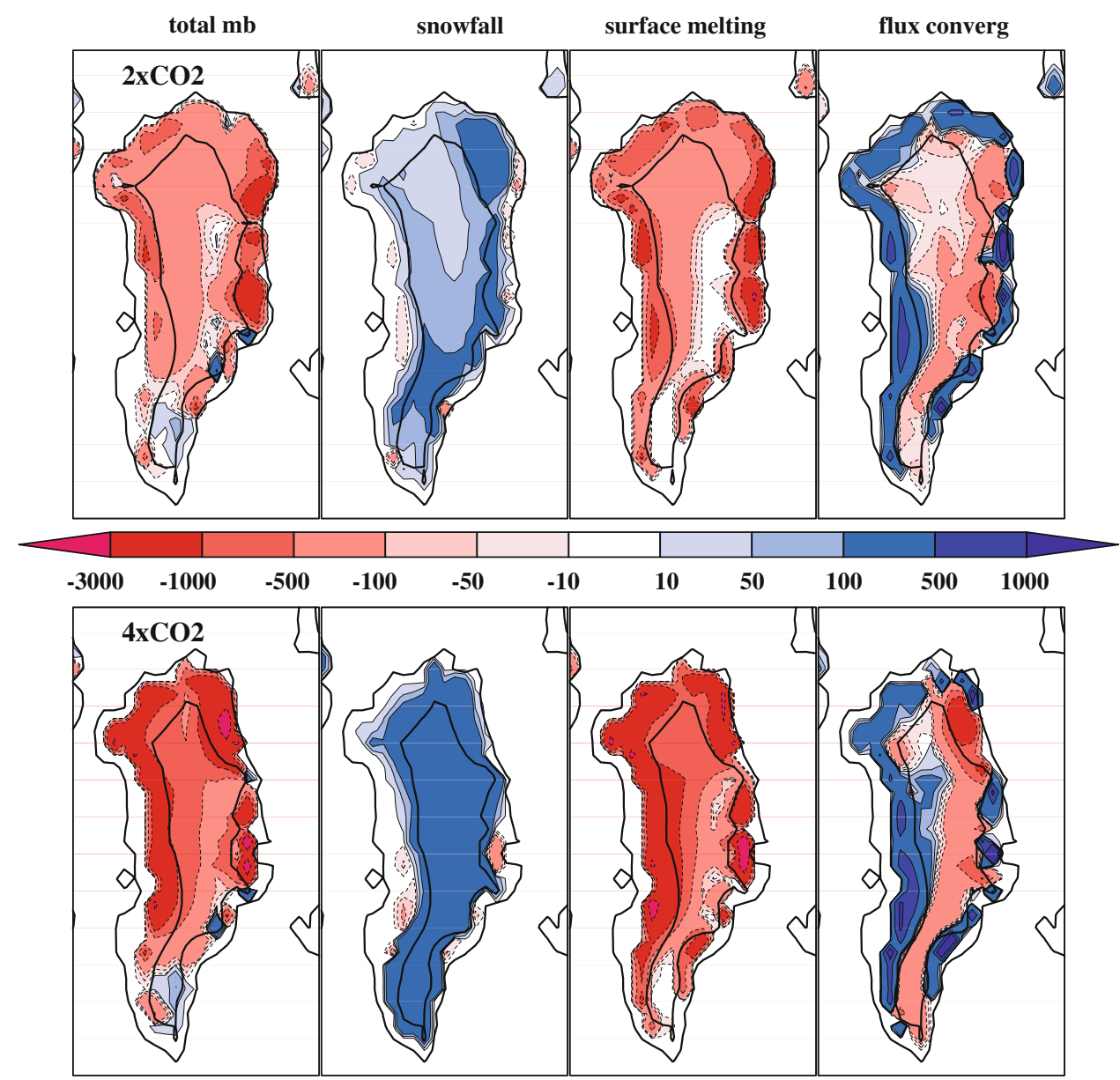

by more than $100 \mathrm{~mm}$ year $^{-1}$ over the entire West AIS and most of the areas of the East AIS with elevations below $3,000 \mathrm{~m}$. Ice fluxes do not change substantially over most of the ice sheet; the biggest changes are simulated in the West AIS.

\subsection{Climate changes induced by interactive ice sheets}

\subsubsection{Modification of the NAMOC by ice sheets}

The increased meltwater fluxes from the decaying GrIS contribute to the total increase in the freshwater forcing of the NAMOC (Fig. 4c). Other contributors are changes in precipitation minus evaporation over the ocean and in river runoff due to the warmer atmosphere and associated enhanced hydrological cycle (see Fig. 5c). The NAMOC weakens substantially by year 100 in all the simulations, whether they include the effect of interactive ice sheets or not (Fig. 4b). At this time, the contribution from the GrIS, which can be estimated as the difference in total fluxes between the simulations with and without interactive ice sheets, is relatively small. The contribution from the GrIS increases in subsequent years. This produces no effect on NAMOC strength in $4 \times \mathrm{CO}_{2}$, where the circulation remains collapsed also in the simulations without additional freshwater fluxes from the ice sheet (Fig. 4b). In $2 \times \mathrm{CO}_{2}$, however, the additional freshwater forcing from the GrIS prevents the NAMOC from recovering during the last centuries. More details are given in Mikolajewicz et al. (2007b).

\subsubsection{Modification of the atmosphere by ice sheets}

In order to evaluate the impact of ice sheets changes on the atmosphere, the simulations $4 \times \mathrm{CO}_{2}$ and $4 \times \mathrm{CO}_{2}$ ct will be compared. Ice sheets can modify atmospheric conditions via changes in e.g., albedo and orography, and indirectly via changes in ocean circulation. These modifications can be local or remote, the later being driven by changes in the atmospheric circulation.

The summer albedo over Greenland decreases by more than 0.40 in some locations at the east and west coasts, due to retreat of the ice sheet (not shown). In the interior of the ice sheet, decreases between 0.05 and 0.10 are caused by the presence of meltwater on the surface, which is parameterized in the atmosphere model as a function of surface temperature (Eq. 6). Similar changes are simulated at the coast of Antarctica, most of them concentrated in the 
Fig. 10 As Fig. 9, for the AIS
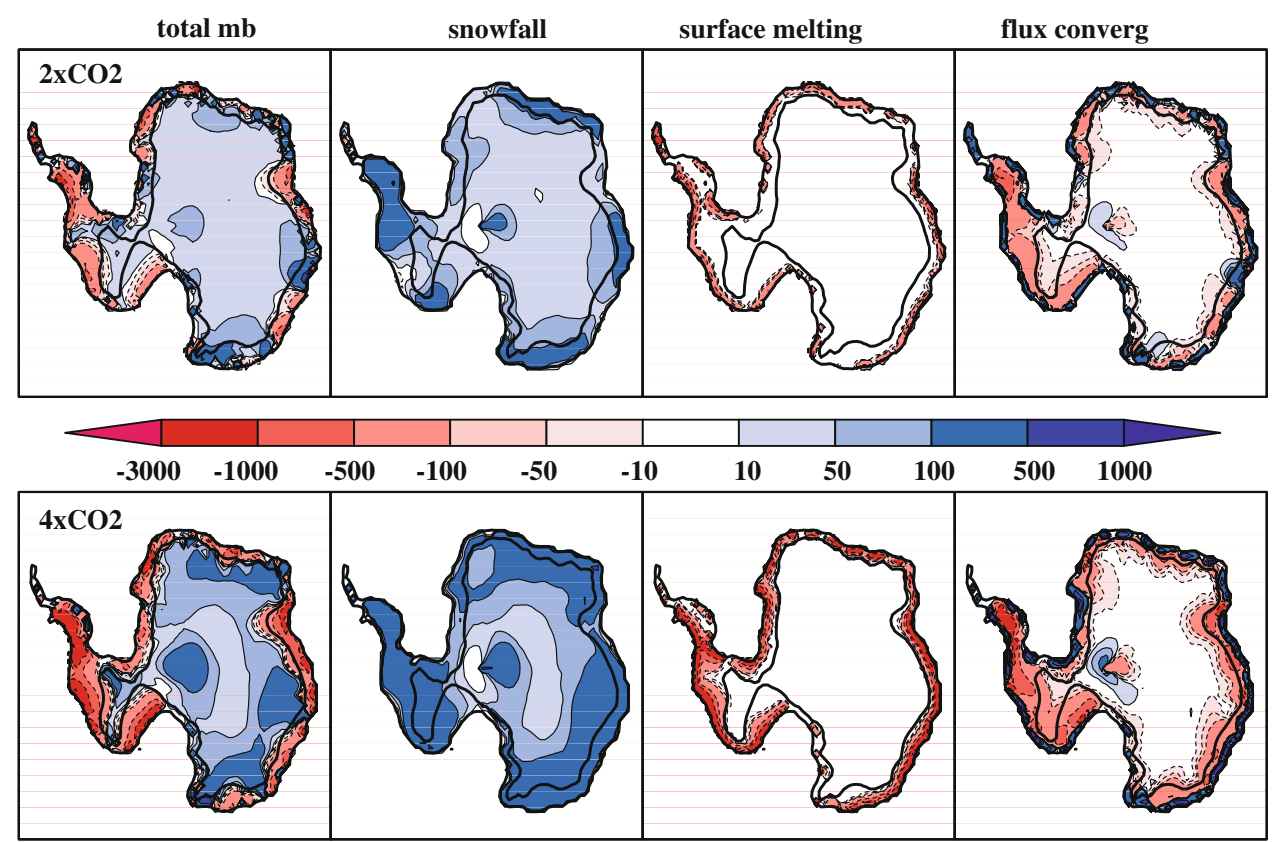

Antarctic Peninsula and the coasts close to the big ice shelves (not modelled within our approach). When interpolated from the ISM grid to the atmospheric grid, the changes in ice thickness described in Sect. 4.3.1 reduce the height of the Greenland Summit in the atmospheric model by more than $500 \mathrm{~m}$. In Antarctica, the main reductions are in the Antarctic Peninsula, the Amundsen Sea coast, and Lambert Glacier. In most of the interior, the topography increases between 20 and $100 \mathrm{~m}$.

The decay of the GrIS produces a local warming of Greenland (Fig. 11a, b) due to reduced topographic height and reduced albedo. In the margins of the ice sheet the warming is stronger in summer than in winter, since it is mainly caused by albedo changes. In the interior of the ice sheet, where most of the warming is caused by reduced topographic height, the warming is weaker in summer. During summer, most of the surface is at or close to melting point in both $4 \times \mathrm{CO}_{2}$ and $4 \times \mathrm{CO}_{2}$ ct. Since surface temperatures over the ice sheet cannot rise above melting point, this imposes a constraint on the increase of nearsurface air temperature. As a result, this increase is smaller in summer.

Remotely, the changes in the topography of the GrIS produce a small cooling of $0.5-2 \mathrm{~K}$ in central Asia during winter (Fig. 11a). In summer, parts of the Norwegian and Barents Seas cool by less than $0.5 \mathrm{~K}$. The size reduction of the Greenland ice sheet modifies the atmospheric circulation, causing these remote climate changes. Figure 12 shows the modifications to the winter atmospheric circulation of the northern hemisphere caused by changes of the GrIS. The trough south of (Fig. 12a) is slightly deepened with the changes in the ice sheet; and the ridge to the east of Greenland is intensified and extended towards the northeast (Fig. 12b). Following Blackmon (1976), the band pass filtered variance (2.5-6 days) of the $500 \mathrm{hPa}$ geopotential height is used as an indication of the position of the storm-tracks (see Fig. 12c). An increase of the stormtrack over Greenland and northeast North America is statistically significant as well as a decrease over central Asia (Fig. 12d).

The decay of the GrIS produces an increase of precipitation over most of the ice sheet except the southern part, where the statistical significance of the changes is small (Fig. 11c). There is also reduced precipitation over the ocean east of Greenland. The southeastern part of Greenland experiences high precipitation rates in today's climate and in our control (Fig. 3) and greenhouse simulations, due to the steep gradient of topography. The orographic barrier forces the occurrence of most of the precipitation at the margin of the ice sheet. As the height of the ice sheet lowers in the greenhouse simulation, a bigger fraction of precipitation falls in the interior of the ice sheet, while a smaller fraction falls over the adjacent ocean. The changes in precipitation shown in Ridley et al. (2005) follow a similar behaviour.

In Antarctica, reduced albedo and topography cause austral summer warming in the Antarctic Peninsula, in the area close to the big ice shelves of the West AIS, in Dronning Maud Land, and in the nearby of Lambert Glacier (Fig. 11a). The reductions in albedo are larger than 0.40 at part of these locations, due to coastal retreat of the ice sheet. This might be somehow unrealistic in the areas of the big ice shelves because, as these are missing, the margin of the ice sheet is initially misplaced. The area 

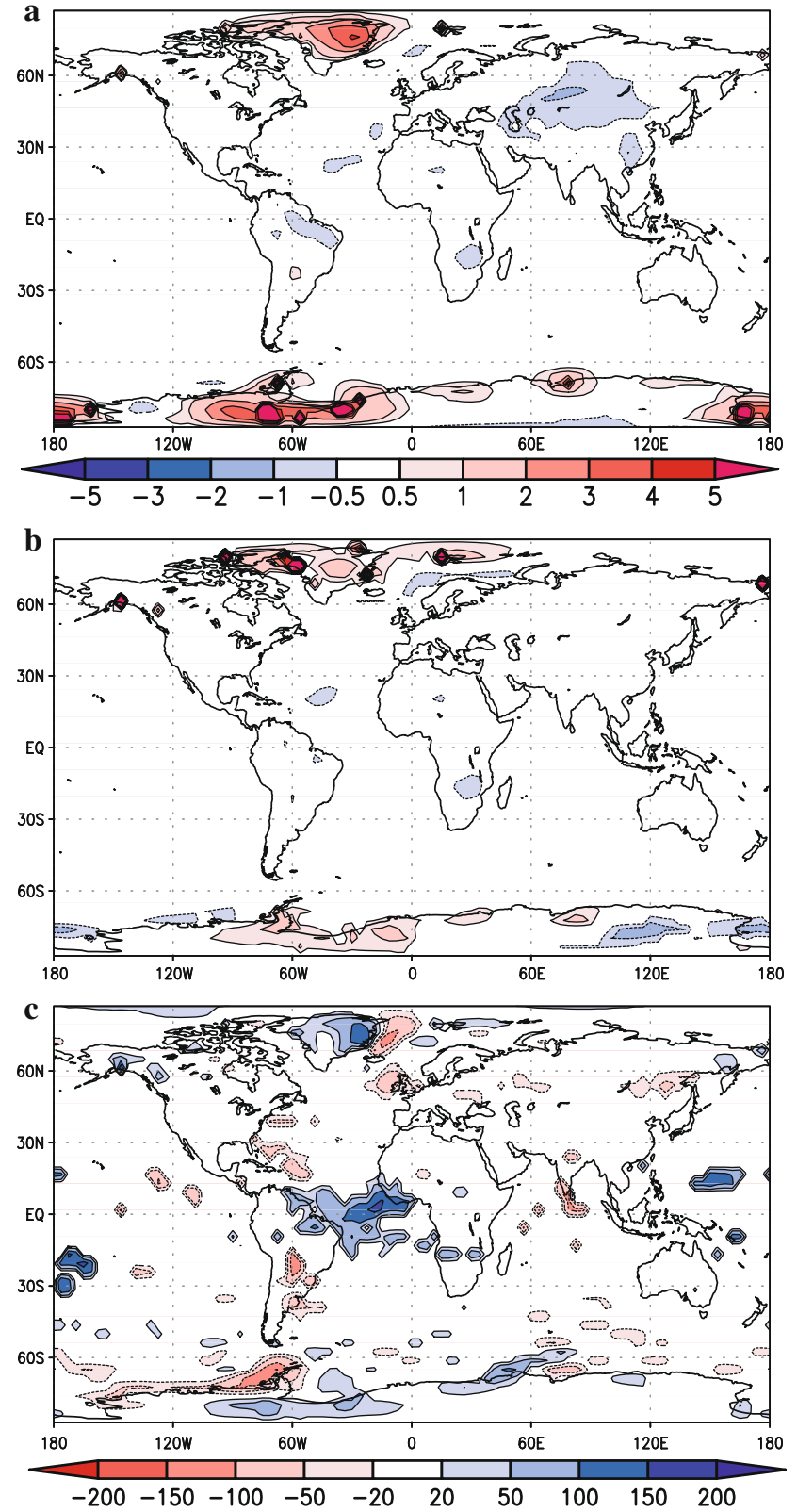

Fig. 11 Changes in atmospheric variables due to interactive ice sheets $\left(4 \times \mathrm{CO}_{2}\right.$ minus $\left.4 \times \mathrm{CO}_{2} \mathrm{ct}\right)$ : near-surface temperature $(\mathrm{K})$ during a winter (DJF) and b summer (JJA); c annual precipitation $\left(\mathrm{mm} \mathrm{year}^{-1}\right)$. Only signals significant at the $95 \%$ confidence level have been plotted

close to the South Pole slightly cools due to higher topography in this region. Winter temperature changes are less than $2 \mathrm{~K}$ in magnitude, with increases over the Antarctic Peninsula, Dronning Maud Land and the nearby of Lambert glacier and the Filchner-Ronne Ice Shelf; and decreases in part of the interior of East Antarctica, where the topographic height has increased.

Precipitation rates decrease over the Antarctic Peninsula and most of the coast of West Antarctica, over the
Bellingshausen and Amundsen seas (Fig. 11c), due to reduced topographic gradient at the former margin of the ice sheet (see changes in thickness, Fig. 8). Precipitation increases over the Filchner-Ronne Ice Shelf and surrounding continental areas. It also increases over Dronning Maud Land and Wilkes Land. Most of these changes seem to be driven by modification of the orographic forcing of precipitation.

\subsection{Effect of ice sheet-climate feedbacks on the mass balance}

In this section we will compare the evolution of the ice sheets in $4 \times \mathrm{CO}_{2}$ and $4 \times \mathrm{CO}_{2} \mathrm{ct}$, in order to identify the impact of local climate modification by the ice sheets on their mass balance. In the simulation $4 \times \mathrm{CO}_{2} \mathrm{ct}$ the change in near-surface temperature due to changing local surface height of the ice sheet is accounted for by a constant prescribed lapse rate of $6.5 \mathrm{~K} \mathrm{~km}^{-1}$. This lapse rate is used to interpolate temperatures from the height of the atmospheric grid to the ISM grid. In the fully coupled simulation $4 \times \mathrm{CO}_{2}$ the surface topography of the atmospheric model varies with time as interpolated from the varying topography of the ice sheet model. The lapse rate of $6.5 \mathrm{~K} \mathrm{~km}^{-1}$ is applied only to account for the height differences caused by the different resolutions of both models. Thus, the effect of the assumed lapse rate (and thus the potential error introduced by this simplification) is much larger in the case of non-interactive ice sheets. In $4 \times \mathrm{CO}_{2}$ ct the surface albedo of the atmospheric grid is neither modified by the retreat of the ice sheet nor by the change of surface temperature connected to height modification (Eq. 6). Finally, atmospheric circulation changes caused by the changing ice sheets are not accounted for in $4 \times \mathrm{CO}_{2}$ ct.

The total volume of the GrIS in $4 \times \mathrm{CO}_{2}$ and $4 \times \mathrm{CO}_{2} \mathrm{ct}$ evolve similarly until year 320 (Fig. 7). Thereafter, the GrIS of $4 \times \mathrm{CO}_{2}$ decays at a lower pace. By year 600 , there is a $28 \%$ reduction of mass loss when a full coupling is considered. This would indicate that the feedbacks between ice sheet and climate reduce the decay rate of the ice sheet (negative feedback), assuming that the direct effect of temperature change due to topographic change is well captured by a lapse rate of $6.5 \mathrm{~K} \mathrm{~km}^{-1}$.

Figure 13 shows the thickness differences of the GrIS and AIS caused by the interactive ice sheets. The associated climate anomalies reduce the local decay of most of the GrIS, except on the northwest, where they accelerate the loss of mass. An analysis of the differences in the different components of the mass budget between years 501 and 600 (Fig. 14) shows that the mass balance differences are dominated by surface melting. Increased melting due to the feedbacks is seen in the northwest and some very small regions in the margins, while most of the ice sheet experiences lower melting rates in the simulation 
Fig. 12 Transient and mean atmospheric circulation in middle and high boreal latitudes in $4 \times \mathrm{CO}_{2} \mathrm{ct}$ and modifications introduced the interactive ice sheets: winter (DJF) geopotential height anomalies relative to the zonal mean at $500 \mathrm{hPa}$ a from $4 \times \mathrm{CO}_{2}$ ct and $\mathbf{b}$ $4 \times \mathrm{CO}_{2}$ minus $4 \times \mathrm{CO}_{2} \mathrm{ct}$; stormtrack in $\mathbf{c} 4 \times \mathrm{CO}_{2}$ ct and d $4 \times \mathrm{CO}_{2}$ minus $4 \times \mathrm{CO}_{2}$ ct. Units are geopotential meters (gpm). Contour lines are plotted every $30,3,5$ and $0.3 \mathrm{gpm}$ in (a),(b), (c), and (d), respectively. The storm track is defined as the band-pass filtered standard deviation of the geopotential height field at $500 \mathrm{hPa}$, as in Blackmon (1976). The grey shading indicates areas where the statistical significance exceeds the $95 \%$ confidence level
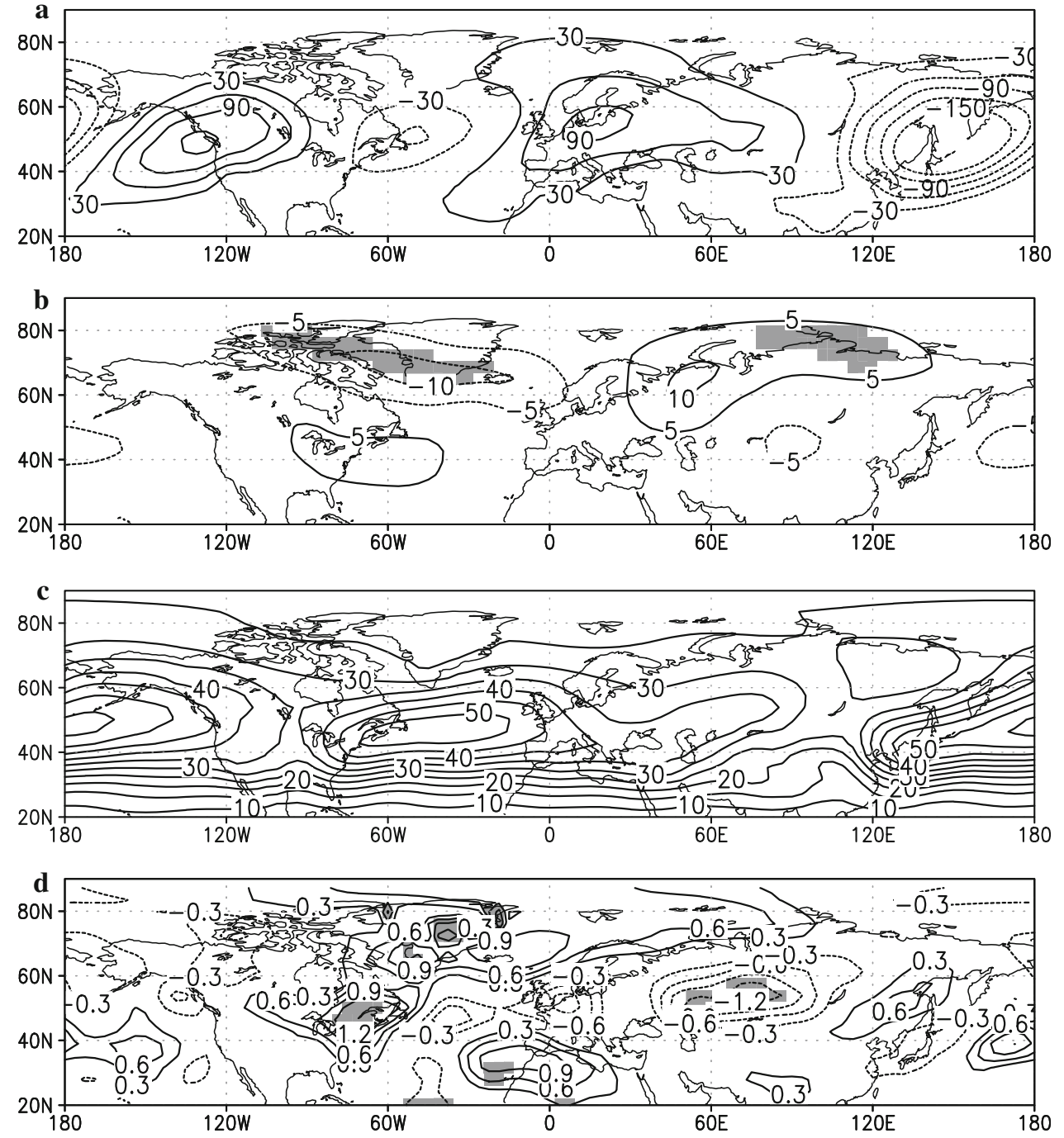

with the fully coupled model. The map of accumulation anomalies shows lower rates in most of the area above $2,000 \mathrm{~m}$, in the area of the northwest corresponding to the positive melting anomaly, and in the southernmost part of the ice sheet. However, the map of precipitation anomalies in the atmospheric model between both simulations (Fig. 11c) shows increased precipitation all over the ice sheet except for the southern tip of Greenland, where the anomalies are not statistically significant at the 95\% level.

In order to explain the differences in melting and accumulation shown in Fig. 14, we correct the temperature and precipitation anomalies from the height differences in the atmospheric model (Fig. 15). This height correction is made in the same way as described in Sect. 2.2 for the downscaling of atmospheric fields from the atmospheric grid onto the ISM grid. After being height-corrected, the positive temperature anomalies of Fig. $11 \mathrm{~b}$ turn negative, except in the region in the northwest that shows increased melting rates (Fig. 14) and in some other coastal regions in the north and the east (Fig. 15b). These negative temperature anomalies do not appear in the winter map (Fig. 15a). This indicates that the increase of summer surface temperature that accompanies the surface-height decrease in the coupled simulation is smaller than the lapse rate of $6.5 \mathrm{~K} \mathrm{~km}^{-1}$ used for the correction, as the linear height correction does not account for the limitation of the near-surface temperature increase caused by the melting surface.

The map of height-corrected precipitation change (Fig. 15c) presents negative anomalies in the interior of the ice sheet at high elevation and in the south of Greenland, and positive in the rest. As shown in Sect. 4.4.2, the interactive GrIS produces an increase of precipitation over the ice sheet as it decays. In the interior, the parameterization used in the downscaling (Eq. 1) overestimates the increase of precipitation that follows the decrease in topographic elevation. This parameterization assumes no changes in lower areas. The increase in precipitation 
Fig. 13 Ice thickness anomalies $(\mathrm{m})$ for $4 \times \mathrm{CO}_{2}$ minus $4 \times \mathrm{CO}_{2}$ ct averaged over years 501-600. The light blue (pink) line delimits areas where the ice sheet has retreated (advanced). The thick black lines indicate the isolines of 0 and 2,000 $\mathrm{m}$ surface elevation
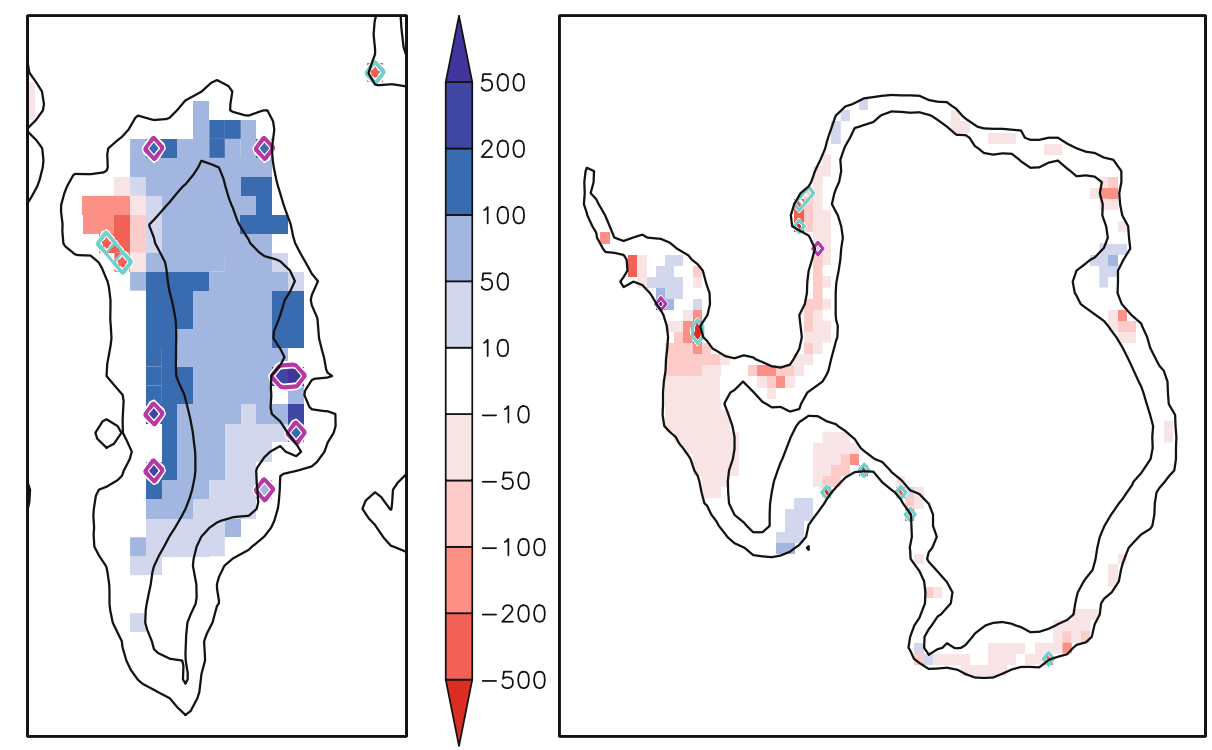

Fig. 14 As Figs. 9 and 10, for $4 \times \mathrm{CO}_{2}$ minus $4 \times \mathrm{CO}_{2}$ ct averaged over years $501-600$

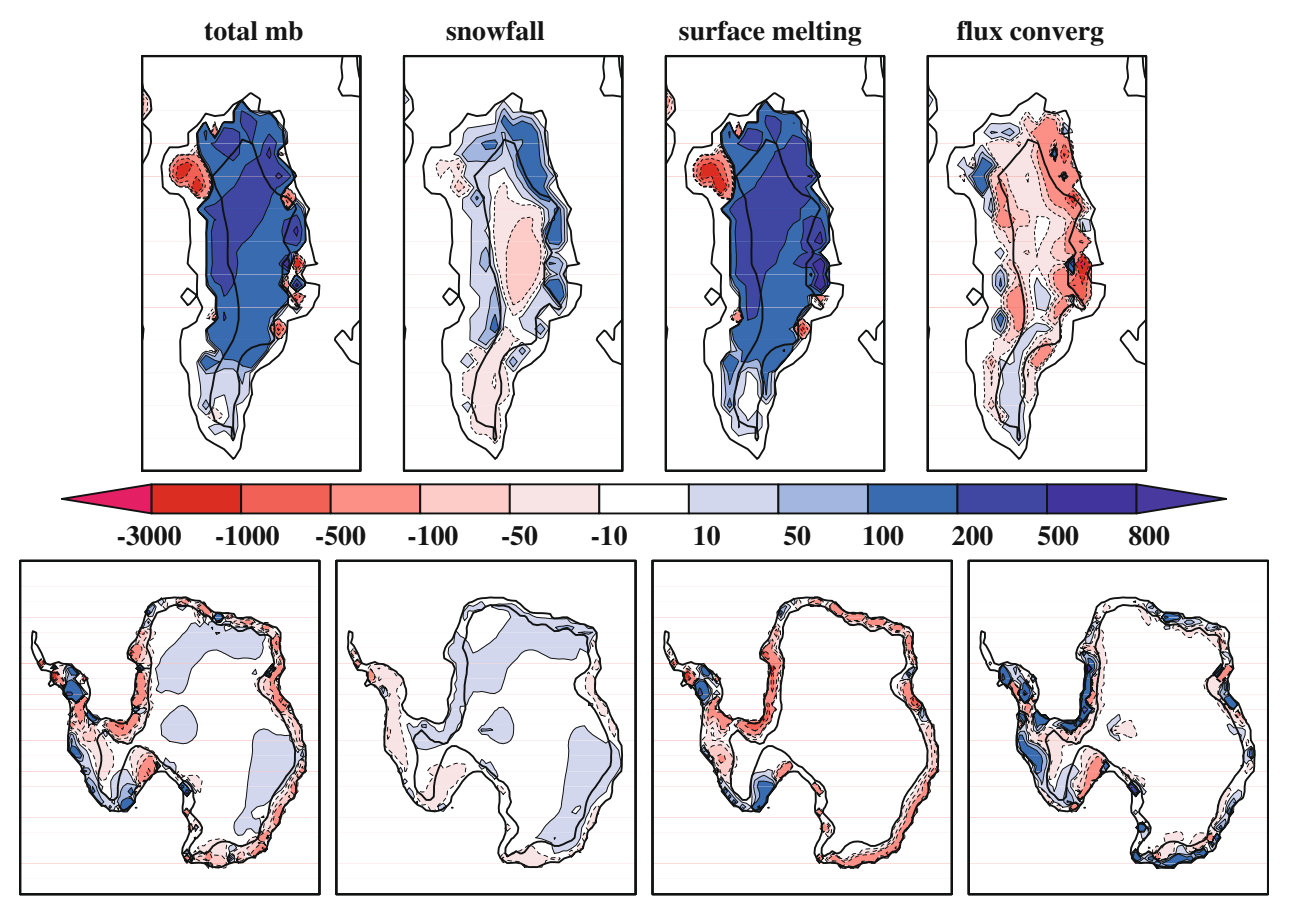

associated with the decay is neglected at the margins of the GrIS in the simulation without interactive ice sheets. In the northwest, the non-interactive simulation does not capture the local increase in the fraction of precipitation falling as rain (Fig. 14). This increase is caused by the local warming that follows from the retreat of the ice sheet (Fig. 11b).

The total volume of the AIS from $4 \times \mathrm{CO}_{2}$ and $4 \times \mathrm{CO}_{2} \mathrm{ct}$ evolves similarly until year 200 (Fig. 7). From then, the local climate changes caused by the ice sheet accelerate its decay (positive feedback). By year 600, the climate modification caused by the interactive ice sheet produces an additional decay of $13 \%$. Most of the additional loss of mass takes place in the Antarctic Peninsula and West AIS, mainly in the Amundsen Sea coast and the coast close to the current grounding line of the Filchner-Ronne ice shelf, which is not simulated within this ISM (Fig. 13). This additional loss of mass is caused by increased surface melting at several locations at the margins (Fig. 14), mainly due to albedo modification. The differences in snowfall between $4 \times \mathrm{CO}_{2}$ and $4 \times \mathrm{CO}_{2}$ ct (Fig. 14) are similar to the differences in the pattern of precipitation anomalies in the atmospheric model (Fig. 11c). 
Fig. 15 Regional climatic changes in Greenland caused by interactive ice sheets $\left(4 \times \mathrm{CO}_{2}\right.$ minus $4 \times \mathrm{CO}_{2}$ ct) corrected from height differences: a winter (DJF) and b summer (JJA) nearsurface temperature $(\mathrm{K})$; $\mathbf{c}$ annual precipitation $\left(\mathrm{mm}\right.$ year $\left.^{-1}\right)$. Average over years 501-600. The height correction is applied as in the downscaling procedure described in Sect. 2.2

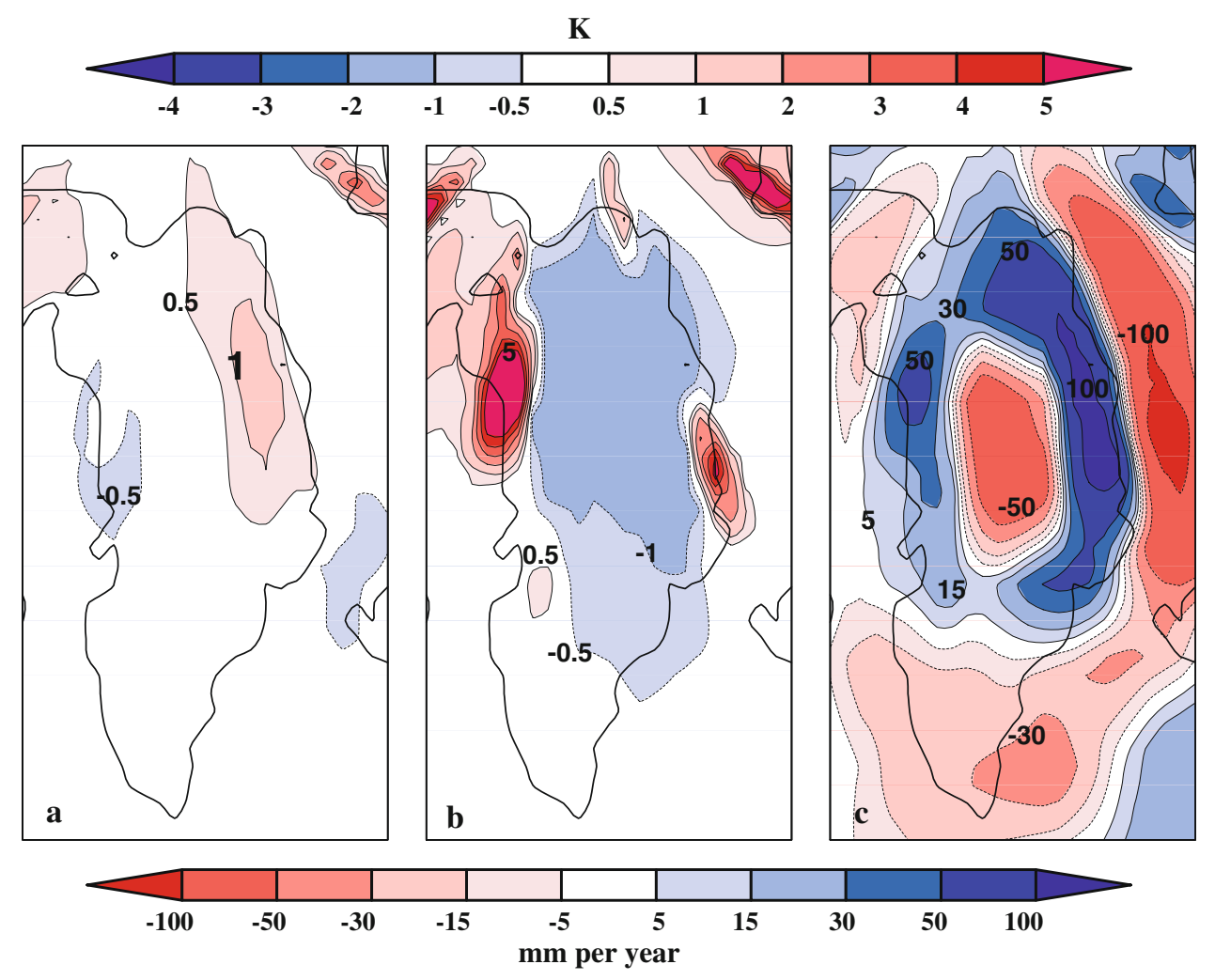

\section{Summary and conclusions}

In this paper, the bi-directional coupling of an ice sheet model to an AOGCM and a dynamical vegetation model is described, and this climate model is applied to the investigation of three questions related with future ice sheets: (1) the evolution of global ice sheets under anthropogenic greenhouse forcing, (2) the modification of climate by these changes in the ice sheets and (3) the modification of the mass balance of the ice sheets due to local climate changes caused by changes in the ice sheets. Current assessments of future sea level rise (e.g., the last IPCC report) do not include the feedbacks, addressed with (3), between ice sheets and climate in their estimates of changes in ice sheet mass balance. With our study, we have aimed to establish whether these feedbacks are important in the mass balance budget and in which time-scales.

A substantial improvement in this study with respect to previous modelling studies, is that the climatic forcing to the ice sheet is applied directly and no anomaly coupling needs to be used. Instead of using climate anomalies superimposed to a present-day observational climatology, the atmospheric fields are applied directly as forcing of the ice sheet model. The use of anomalies is required when the simulated climate suffers from important biases that would drive the ice sheet model to an unrealistic regime. The drawback is that they cause inconsistencies between the climate of the atmospheric and ice sheet components and this may distort the way in which climate-ice sheet feedbacks operate. An analogous improvement in the coupling of different climate components took place in the recent past when AOGCMs with anomaly coupling were replaced by the current generation of AOGCMs.

An additional strength of our model is that the calculation of surface mass balance has been performed with an energy balance scheme, which is more suitable for climate change simulations than the more simple approach of using a positive degree-day calculation (Bougamont et al. 2007).

The response of the ice sheets to anthropogenic greenhouse forcing has been investigated under two idealized scenarios of doubling and quadrupling of atmospheric carbon dioxide concentrations. After 600 years of simulation, the Greenland ice sheet looses 11 and 35\% of its original volume in the doubling and quadrupling simulations, respectively. The Antarctic ice sheet gains mass ( $0.2 \%$ of its original volume) in the doubling simulation due to increased snowfall but looses $2 \%$ of its initial volume in the quadrupling simulation. It must be noted that our ice sheet model does not simulate either ice shelves nor ice streams, and has a limited resolution $(80 \mathrm{~km})$. Therefore, projections of changes in the mass balance caused by rapid changes in the small-scale fast flowing components of the ice sheets, such as outlet glaciers or the narrow ice streams, have not been included in this study. However, numerous studies (e.g., Joughin et al. 2003; Scambos et al. 2004; Rignot and Kanagaratnam 2006; Shepherd and 
Wingham 2007) indicate that these dynamical changes are the main drivers of current mass balance change and might be also be the main drivers of future change. In the case of Antarctica, the lack of ice shelves in our model represents a severe limitation of our study.

Increased freshwater fluxes from the Greenland ice sheet do not play a role in the weakening of the North Atlantic Meridional Overturning Circulation. In our model, this weakening takes place during the first 100-130 years of the simulations (Fig. 4b), when the freshwater fluxes from the ice sheets are small in comparison with the total net freshwater fluxes anomalies into the North Atlantic and Arctic. At this time, the changes in total fluxes are dominated by increased precipitation over the ocean and increased river runoff (Fig. 4c). However, the modification of ocean density by increased freshwater fluxes from the Greenland ice sheet seems to play an important role in hindering the recovery of the ocean circulation at a later stage.

The impact of a reduction by $1 / 3$ of the size of the Greenland ice sheet on non-local near-surface temperatures seems to be unimportant at high latitudes. The modification of the mean and transient atmospheric circulations caused by this size change produces only a small cooling in central Asia (Fig. 11a). Several modelling studies investigating the impact of the complete removal of the ice sheet show a cooling over Scandinavia and Barents Sea (Junge et al. 2005; Ridley et al. 2005; Lunt et al. 2004) or the Laptev Sea (Vizcaíno et al. 2008). The absence of a significant impact at high latitudes in our model might be due to the smaller size of the topographic perturbation introduced (1/3 vs. full size) and, more importantly perhaps, the fact that the Arctic ocean is ice-free year-around by the end of our quadrupling simulation. As a consequence of this, the meridional temperature contrast between middle and high latitudes is reduced, and modifications of the atmospheric circulation to a more zonal flow due to the reduced topographic obstacle do not cause significant changes in heat advection in the areas east of Greenland. Another consequence of the absence of sea ice is that initial perturbations over the high latitude ocean are not amplified by sea ice feedbacks.

Locally, the retreat of the Greenland ice sheet and its replacement by boreal forest produces a strong warming at the margins, due to albedo changes of more than 0.40 . In the interior of the ice sheet, temperature anomalies caused by the changes in the ice sheet are bigger in winter than in summer. By the year 600 of our quadrupling simulation, an interactive Greenland ice sheet reduces its own mass loss by $28 \%$ with respect to the case of a passively coupled ice sheet. In most of the Greenland ice sheet, melting rates are reduced in the fully coupled case, except in the areas of the ice sheet close to retreating margins, where ablation heavily increases as a result of lower albedos. The differences in melting rates over the rest of the ice sheet are caused by the differences in the modelling of the heighteffect, e.g., the thermodynamical change in near-surface temperature that follows a change in surface height. When the ice sheet is not interactively coupled, the downscaling of the atmospheric forcing accounts for the differences between the fixed topography of the atmospheric model and the evolving topography of the ice sheet model. This is done via constant lapse rates. With interactive coupling, the topography of the atmospheric model evolves with the changing ice sheets, and the height differences between both model grids are reduced. When most of the ice surface reaches melting point due to increasing global warming, the atmospheric lapse rate begins to depart from the prescribed lapse rate of the downscaling. As a result, the increase in near-surface temperature and melting is less than assumed in the non-interactive simulation. The use of interactive coupling, therefore, reduces the bias introduced by using prescribed lapse rates in the downscaling of the atmospheric forcing. Before year 320 of our $4 \times \mathrm{CO}_{2}$ simulation the effect is small in an integrated sense, as the effects of modified albedos and surface height largely cancel each other.

In our simulations, the modelling of the height-effect dominates the suite of perturbations caused by the GrIS as an active component of the climate system contributing to shape its own evolution. This calls for careful consideration of the lapse rate used in the downscaling of atmospheric forcing to the higher-resolution grid of the ice sheet model, particularly in simulations without interactive ice sheets with substantial changes in the original topography.

Our results suggest that a future size reduction of the Greenland ice sheet would increase precipitation rates over Greenland, due to thermodynamical and dynamical effects: the change in air moisture with altitude caused by temperature change, changes in the orographic forcing of precipitation, and changes in the storm-track. This agrees with results from other modelling studies (Toniazzo et al. 2004; Ridley et al. 2005).

In Antarctica, the main climatic effects of the changing interactive ice sheet on the mass balance of the ice sheet is an increase of melting rates at the margins, which enhances the decay rate of the ice sheet (positive feedback, Fig. 7). This enhancement is caused mainly by lower coastal albedos in areas where the ice sheet retreats.

One main conclusion of our study is that the noninclusion of ice sheet-climate feedbacks in the projections of future changes in the ice sheets is likely to result in errors of the mass balance, which, however, are not very large before year 320 of our simulations. Two potential sources of error have been identified as important: the height-effect and the albedo changes caused by ice sheet 
retreat. The height-effect needs to be explicitly modelled, among other reasons, because close-to-melting-point glacier surfaces impose a limit to near-surface temperature increase. The albedo changes associated with ice sheet retreat are big in magnitude, and modify strongly the local conditions. It is important to note that low resolutions in the atmospheric and ice sheet models and/or the absence of a fractional glacier mask in the atmospheric model can limit the impact of ice sheet retreat on the mass balance.

In summary, our results confirm that the ice sheets should not be considered exclusively as a passive component of the climate system in projections of anthropogenic climate change. Modifications of their volume, extent and shape have an impact on the climate system, and feed back on their own mass balance as well.

Acknowledgments This work was performed within the project CLIMCYC, funded by the DEKLIM program of the German Ministry of Education and Research. The simulations have been performed at the "Deutsches Klimarechenzentrum" (DKRZ). Prof. Ralf Greve is thanked for his support with the ice sheet model, Abigail Swann and Andrew Friedman for their help with the style and grammar of the manuscript, and Luis Berbil for his help with the preparation of figures. The two anonymous reviewers are thanked for their contribution to the improvement of the manuscript.

\section{References}

Abdalati W, Steffen K (1997) Snowmelt on the Greenland Ice Sheet as derived from passive microwave satellite data. J Clim 10:165-175. doi:10.1175/1520-0442(1997)010<0165:SOTGIS >2.0.CO;2

Ambach W, Kirchlechner P (1986) Nomographs for the determination of the meltwater from ice and snow surfaces by sensible and latent heat flux. Wetter Leben 38:181-189

Arakawa A, Lamb VR (1977) Computational design of the basic dynamical processes of the UCLA general circulation model. Methods Comput Phys 17:173-265

Blackmon M (1976) A climatological spectral study of the $500 \mathrm{mb}$ geopotential height of the Northern Hemisphere. J Atmos Sci 33:1607-1623. doi:10.1175/1520-0469(1976)033<1607:ACSSOT> 2.0.CO;2

Bougamont M, Bamber JL, Ridley JK, Gladstone RM, Greuell W, Hanna E, Payne AJ, Rutt I (2007) Impact of model physics on estimating the surface mass balance of the Greenland ice sheet. Geophys Res Lett 34:L17501. doi:10.1029/2007GL030700

Box JE, Bromwich DH, Bai LS (2004) Greenland ice sheet surface mass balance 1991-2000: application of polar MM5 mesoscale model and in situ data. J Geophys Res 109:D16105. doi: 10.1029/2003JD004451

Budd WF, Smith IN (1979) The growth and retreat of ice sheets in response to orbital radiation changes. In: Sea level, ice, and climatic change, Proceedings of the Canberra Symposium, December 1979, IAHS Publication no. 131

Calov R, Marsiat I (1998) Simulations of the Northern Hemisphere through the last glacial-interglacial cycle with a vertically integrated and a three-dimensional thermomechanical ice sheet model coupled to a climate model. Ann Glaciol 27:169-176

Calov R, Ganopolski A, Claussen M, Petoukhov V, Greve R (2005) Transient simulation of the last glacial inception. Part I: glacial inception as a bifurcation in the climate system. Clim Dyn 24:545-561. doi:10.1007/s00382-005-0007-6

Church JA, Gregory JM, Huybrechts P, Kuhn M, Lambeck K, Nhuan MT, Qin D, Woodworth PL (2001) Changes in sea level. In: Houghton JT, Ding Y, Griggs DJ, Noguer M, Van Der Linden PJ, Dai X, Maskell K, Johnson CA (eds) Climate change 2001: the scientific basis. Cambridge University Press, Cambridge, pp 640-693

Dansgaard WS, Johnsen S, Clausen H, Dahl-Jensen D, Gunestrup N, Hammer C, Hvidberg C, Steffensens J, Sveinbjörnsdottir A, Jouzel J, Bond G (1993) Evidence for general instability of past climate from a 250-kyr ice-core record. Nature 364:218-220. doi: $10.1038 / 364218 \mathrm{a} 0$

ETOPO5 (1988) Data announcement 88-mgg-02, digital relief of the surface of the earth. Technical report NOAA, National Geophysical Data Center, Boulder

Fouquart Y, Bonnel B (1980) Computations of solar heating of the earth's atmosphere- A new parameterization. Beitr Phys Atmos 59:35-62

Gallee H, Ypersele JP, Fichefet T, Marsiat I, Tricot C, Berger A (1992) Simulation of the last glacial cycle by a coupled, sectorially averaged climate-ice sheet model: 2. Response to insolation and $\mathrm{CO}_{2}$ variations. J Geophys Res 97(14):15,71315740

Greve R (1997) Application of a polythermal three-dimensional ice sheet model to the Greenland ice sheet: response to steady-state and transient climate scenarios. J Clim 10:901-918. doi: 10.1175/1520-0442(1997)010<0901:AOAPTD > 2.0.CO;2

Greve R (2000) On the response of the Greenland ice sheet to greenhouse climate change. Clim Chang 46:289-303. doi: 10.1023/A:1005647226590

Greve R, Wyrwoll K, Eisenhauer A (1999) Deglaciation of the Northern Hemisphere at the onset of the Eemian and the Holocene. Ann Glaciol 28:1-8. doi:10.3189/172756499781 821643

Hagemann S, Dümenil-Gates L (1998) A parameterization of the lateral waterflow for the global scale. Clim Dyn 14:17-31. doi: $10.1007 / \mathrm{s} 003820050205$

Hagemann S, Dümenil-Gates L (2003) An improved sub grid runoff parameterization scheme for climate models. Clim Dyn 21:349359. doi:10.1007/s00382-003-0349-x

Hibler WDIII (1979) A dynamic thermodynamic sea ice model. J Phys Oceanogr 9(4):815-846. doi:10.1175/1520-0485(1979) 009<0815:ADTSIM >2.0.CO;2

Huybrechts P, de Wolde J (1999) The dynamic response of the Greenland and Antarctic ice sheets to multiple-century climatic warming. J Clim 12:2169-2188. doi:10.1175/1520-0442(1999) 012<2169:TDROTG $>2.0 . \mathrm{CO} ; 2$

Huybrechts P, Gregory J, Janssens I, Wild M (2004) Modelling Antarctic and Greenland volume changes during the 20th and 21 st centuries forced by GCM time slice integrations. Glob Planet Change 42:83-105. doi:10.1016/j.gloplacha.2003.11.011

Imbrie J, Martinson J, McIntyre D, Mix A, Morley J, Pisias N, Prell W, Shackleton N (1984) The orbital theory of Pleistocene climate: support from a revised chronology of the marine delta $0^{18}$ record. In: Berger A (ed) Milankovich and climate, part I, vol 126. D. Reidel Publishing Company, Dordrecht

Joughin I, Rignot E, Rosanova CE, Lucchitta BK, Bohlander J (2003) Timing of recent accelerations of Pine Island Glacier, Antarctica. Geophys Res Lett 30(13):1706. doi:10.1029/2003GL017609

Jouzel J, Barkov NI, Barnola JM, Bender M, Chappelaz J, Genthon C, Kotlyakov VM, Lipenkov V, Lorius C, Petit JR, Raynaud D, Raisbeck G, Ritz C, Sowers T, Stievenard M, Yiou F, Yiou P (1993) Extending the Vostok ice-core record of paleoclimate to the penultimate glacial period. Nature 364:407-412. doi: $10.1038 / 364407 \mathrm{a} 0$ 
Jouzel J, Waelbroeck C, Malaize B, Bender M, Petit JR, Barkov NI, Barnola JM, King T, Kotlyakov VM, Lipenkov V, Lorius C, Raynaud D, Ritz C, Sowers T (1996) Climatic interpretation of the recently extended Vostok ice records. Clim Dyn 12:513-521. doi:10.1007/BF00207935

Jungclaus JH, Keenlyside N, Botzet M, Haak H, Luo JJ, Latif M, Marotzke J, Mikolajewicz U, Roeckner E (2006) Ocean circulation and tropical variability in the coupled model ECHAM5/ MPI-OM. J Clim 19:3952-3972. doi:10.1175/JCLI3827.1

Junge MM, Blender R, Fraedrich K, Gayler V, Luksch U, Lunkeit F (2005) A world without Greenland: impacts on the Northern Hemisphere winter circulation in low- and high-resolution models. Clim Dyn 24:297-307. doi:10.1007/s00382-004-0501-2

Kageyama M, Charbit S, Ritz C, Khodri M, Ramstein G (2004) Quantifying ice-sheet feedbacks during the last glacial inception. Geophys Res Lett 31:L24203. doi:10.1029/2004GL021339

Le Meur E, Huybrechts P (1998) Present-day uplift patterns over Greenland from a coupled ice-sheet/visco-elastic bedrock model. Geophys Res Lett 25:3951-3954. doi:10.1029/1998GL900052

Lin S, Rood R (1996) Multidimensional flux-form semi-lagrangian transport schemes. Mon Weather Rev 124:2046-2070. doi: 10.1175/1520-0493(1996)124<2046:MFFSLT > 2.0.CO;2

Lohman U, Roeckner E (1996) Design and performance of a new cloud microphysics scheme developed for the ECHAM general circulation model. Clim Dyn 12:557-572. doi:10.1007/BF00207939

Lunt D, de Noublet-Ducoudré N, Charbit S (2004) Effects of a melted Greenland ice sheet on climate, vegetation, and the cryosphere. Clim Dyn 23:679-694. doi:10.1007/s00382-004-0463-4

Marsland S, Haak H, Jungclaus J, Latif M, Röske F (2003) The MaxPlanck-Institute global ocean/sea ice model with orthogonal curvilinear coordinates. Ocean Model 5:91-127. doi:10.1016/ S1463-5003(02)00015-X

Marty C, Philipona R, Fröhlich C, Ohmura A (2002) Altitude dependence of surface radiation fluxes and cloud forcing in the alps: results from the alpine surface radiation budget network. Theor Appl Climatol 72(3-4):137-155. doi:10.1007/s007040200019

Meehl GA, Stocker TF, Collins WD, Friedlingstein P, Gaye AT, Gregory JM, Kitoh A, Knutti R, Murphy JM, Noda A, Raper SCB, Watterson IG, Weaver AJ, Zhao ZC (2007) Global climate projections. In: Solomon S, Qin D, Manning M, Chen Z, Marquis M, Averyt KB, Tignor M, Miller HL (eds) Climate Change 2007: The physical science basis. Contribution of Working Group I to the Fourth Assessment Report of the Intergovernmental panel on climate change. Cambridge University Press, Cambridge

Mernild SH, Liston GE, Hiemstra CA, Steffen K (2008) Surface melt area and water balance modeling on the Greenland Ice Sheet 1995-2005. J Hydrometeorol 9(6):1191-1211. doi:10.1175/ 2008JHM957.1

Mikolajewicz U, Gröger M, Maier-Reimer E, Schurgers G, Vizcaíno $\mathrm{M}$, Winguth A (2007a) Long-term effects of anthropogenic $\mathrm{CO}_{2}$ emissions simulated with a complex earth system model. Clim Dyn 28:599-633. doi:10.1007/s00382-006-0204-y

Mikolajewicz U, Vizcaíno M, Jungclaus J, Schurgers G (2007b) Effect of ice sheet interactions in anthropogenic climate change simulations. Geophys Res Lett 34:L18706. doi:10.1029/2007GL031173

Morcrette J, Clough SA, Mlawer E, Iacono MJ (1998) Impact of a validated radiative transfer scheme, RRTM, on the ECMWF model climate and 10-day forecasts. ECMWF Technical Memo No. 252

Nordeng T (1994) Extended versions of the convective parameterization scheme of ECMWF and their impact on the men transient activity of the model in the tropics. Technical Memorandum 206, ECMWF: Reading, UK

Ohmura A, Calanca P, Wild M, Anklin M (1999) Precipitation, accumulation and mass balance of the Greenland ice sheet. Zeitschr Gletscherk Glazialgeol 35:1-20
Paterson WSB (1994) The physics of glaciers, 3rd edn. Pergamon Press, Oxford, $480 \mathrm{pp}$

Raper S, Braithwaite R (2006) Low sea level rise projections from mountain glaciers and icecaps under global warming. Nature 439:311-313

Reeh N, Mayer C, Miller H, Thomson HH, Weidick A (1999) Present and past climate control on fjord glaciations in Greenland: implications for IRD-deposition in the sea. Geophys Res Lett 26:1039-1042. doi:10.1029/1999GL900065

Ridley JK, Huybrechts P, Gregory JM, Lowe JA (2005) Elimination of the Greenland Ice Sheet in a High $\mathrm{CO}_{2}$ Climate. J Clim 18:3409-3427. doi:10.1175/JCLI3482.1

Rignot E, Kanagaratnam P (2006) Changes in the velocity structure of the Greenland Ice Sheet. Science 311(5763):986-990. doi: 10.1126/science. 1121381

Roeckner E, Baeuml G, Bonaventura L, Brokopf R, Esch M, Giorgetta M, Hagemann S, Kirchner I, Kornblueh L, Manzini E, Rhodin A, Schlese U, Schulzweida U, Tompkins A (2003) The atmospheric general circulation model ECHAM5. PART I: Model description. Report 349, Max Planck Institute for Meteorology, Hamburg, Germany. Available from http://www. mpimet.mpg.de

Roeckner E, Brokopf R, Esch M, Giorgetta M, Hagemann S, Kornblueh L, Manzini E, Schlese U, Schulzweida U (2006) Sensitivity of simulated climate to horizontal and vertical resolution in the ECHAM5 atmosphere model. J Clim 19:3771-3791. doi: 10.1175/JCLI3824.1

Savviin AA, Greve R, Calov R, Muegge B, Hutte K (2000) Simulation of the Antarctic ice sheet with a three-dimensional polythermal ice-sheet model, in support of the EPICA project II. Nested high-resolution treatment of Dronning Maud Land, Antarctica. Ann Glaciol 30:69-75

Scambos TA, Bohlander JA, Shuman CA, Skvarca P (2004) Glacier acceleration and thinning after ice shelf collapse in the Larsen B embayment, Antarctica. Geophys Res Lett 31:L18402. doi: 10.1029/2004GL020670

Schurgers G, Mikolajewicz U, Gröger M, Maier-Reimer E, Vizcaíno M, Winguth A (2007) The effect of land surface changes on Eemian climate. Clim Dyn 29(4):357-373. doi:10.1007/s00382007-0237-x

Schwerdtfeger (1963) Theoretical derivation of the thermal conductivity and diffusivity of snow. IASH 61:75-81

Schytt V (1958) Glaciology, II. The inner structure of the ice shelf at Maudheim as shown by core drilling. Norw Br Swed Antarct Exped Scient Results 4C:113-151

Sclatter JG, Jaupart C, Galson D (1980) The heat flow through oceanic and continental crust and the heat loss of the earth. Rev Geophys Space Phys 18(1):269-311. doi:10.1029/RG018i001 p00269

Shepherd A, Wingham D (2007) Recent sea-level contributions of the Antarctic and Greenland Ice Sheets. Science 315:1529-1532. doi:10.1126/science.1136776

Sitch S, Smith B, Prentice I, Arneth A, Bondeau A, Cramer W, Kaplan J, Levis S, Lucht W, Sykes M, Thonicke K, Venevsky S (2003) Evaluation of ecosystem dynamics, plant geography and terrestrial carbon cycling in the LPJ dynamic global vegetation model. Glob Chang Biol 9(2):161-185. doi:10.1046/j.13652486.2003.00569.x

Tiedke M (1989) A comprehensive mass flux scheme for cumulus parameterization in large-scale models. Mon Weather Rev 117:1779-1800. doi:10.1175/1520-0493(1989)117<1779: ACMFSF $>2.0 . \mathrm{CO} ; 2$

Toniazzo T, Gregory JM, Huybrechts P (2004) Climate impact of a Greenland deglaciation and its possible irreversibility. J Clim 17:21-33. doi:10.1175/1520-0442(2004)017<0021:CIOAGD> 2.0.CO;2 
Uppala SM, Kallberg PW, Simmons AJ, Andrae U, da Costa Bechtold V, Fiorino M, Gibson J, Haseler J, Hernandez A, Kelly G, Li X, Onogi K, Saarinen S, Sokka N, Allan R, Andersson E, Arpe K, Balmaseda M, Beljaars A, van de Berg L, Bidlot J, Bormann N, Caires S, Chevallier F, Dethof A, Dragosavac M, Fisher M, Fuentes M, Hagemann S, Holm E, Hoskins B, Isaksen L, Janssen P, Jenne R, McNally A, Mahfouf JF, Morcrette JJ, Rayner N, Saunders R, Simon P, Sterl A, Trenberth K, Untch A, Vasiljevic D, Viterbo P, Woollen J (2005) The ERA-40 re-analysis. Q J R Meteorol Soc 131:2961-3012. doi:10.1256/qj.04.176

Valcke S, Caubel A, Declat D, Terray L (2003) OASIS Ocean atmosphere sea ice soil user's guide. Technical report TR/ CMGC/03/69, CERFACS, Toulouse, France. p 85

van de Berg WJ, van den Broeke MR, Reijmer $\mathrm{CH}$, van Meijgaard E (2006) Reassessment of the Antarctic surface mass balance using calibrated output of a regional atmospheric climate model. J Geophys Res 111:D11104. doi:10.1029/2005JD006495 van de Wal RSW (1996) Mass-balance modelling of the Greenland ice sheet: a comparison of an energy-balance and a degree-day model. Ann Glaciol 23:36-45

Vizcaíno M, Mikolajewicz U, Jungclaus J, Schurgers G (2008) Longterm ice sheet-climate interactions under anthropogenic greenhouse forcing simulated with a complex Earth System Model. Clim Dyn 31:665-690. doi:10.1007/s00382-008-0369-7

Wang Z, Mysak L (2002) Simulation of the last glacial inception and rapid ice sheet growth in the McGill Paleoclimate model. Geophys Res Lett 29(23):2102. doi:10.1029/2002GL015120

Weertman J (1964) The theory of glacier sliding. J Glaciol 5:287-303

Wolff JE, Maier-Reimer E, Legutke S (1997) The Hamburg Ocean primitive equation model-HOPE. Technical Report 13, German Climate Computer Centre (DKRZ), Hamburg, Germany

Yen YC (1981) Review of thermal properties of snow, ice and sea ice. CRREL Report, 81-10 